\title{
On the $\mathrm{CO}_{2}$ Emissions of the Global Electricity Supply Sector and the Influence of Renewable Power- Modeling and Optimization
}

\author{
Tino Aboumahboub ${ }^{1 *}$, Katrin Schaber ${ }^{1,2}$ \\ Ulrich Wagner ${ }^{1}$, Thomas Hamacher ${ }^{1,2}$ \\ ${ }^{1}$ Institute for Energy Economy and Application Technology, Technische Universität München, \\ Arccisstr.21, 80333 Munich, Germany \\ ${ }^{2}$ Research Group for Energy and Systems Studies, Max Planck Institute for Plasma Physics \\ Boltzmannstr. 2, D-85748 Garching, Germany
}

\begin{abstract}
This study investigates influences of different factors on the $\mathrm{CO}_{2}$ emissions of the global electricity generation system. The analysis has been performed through applying an electricity system investment and production optimization model based on linear programming. This model has been calibrated according to the real electricity generation data.

The results show that the introduction of a global $\mathrm{CO}_{2}$-certificate price of $18 € / \mathrm{t}$ would lead to a total abatement of several hundreds of million tons in 2006, i.e. $5 \%$ reduction of emissions compared to the baseline scenario without any carbon price.
\end{abstract}

Through a sensitivity study, we show that in addition to the $\mathrm{CO}_{2}$-certificate price, relation between natural gas and coal price is crucial for the abatement achieved through fuel switching.

On a long-term horizon, integration of wind is determined as the most economic option to respond to ambitious emissions reduction targets. A wind power capacity of 4913 GW in 2020 and 15729 GW by 2040 allows reducing the emissions by $35 \%$ and $78 \%$, respectively, as compared to the emissions of year 2000 while the $\mathrm{CO}_{2}$-price rises from 18 to $44 € /$ ton. This can only be achieved if the capacities of cross-border power transmission interconnections are extended far beyond the existing levels.

Keywords: Electricity supply sector; $\mathrm{CO}_{2}$ emissions abatement; Fluctuating renewable energy sources

\footnotetext{
"Corresponding author. Tel: +49 89 28923943; Fax: +49 8928928313.

E-mail address: tino.aboumahboub@tum.de
} 


\section{Introduction}

The world is facing global challenging issues of climate change. $\mathrm{CO}_{2}$ is one of the main contributors in the global warming phenomenon; its concentration has risen from a pre-industrial level of about 280 ppmv to more than 380 ppmv (Nakicenovic, 2007). Although, industrialized world regions have initiated climate policies, scenario studies indicate that green house gas emissions (GHG) are likely to increase in most world regions (IPCC, 2000). To ensure that $\mathrm{CO}_{2}$ concentrations stabilize at target levels (IPCC, 2007; Nakicenovic, 2007), a significant reduction of the global emissions is required. This can only be achieved if efficient economical and political incentives are set up. It has been shown that without a near-term introduction of supportive and effective policy actions by governments, annual global GHG emissions are projected to rise from $9.7 \mathrm{Gt} \mathrm{CO}_{2}$-eq in 2000 to $36.7 \mathrm{Gt} \mathrm{CO}_{2}$-eq in 2030 (IPCC, 2007). The energy-related $\mathrm{CO}_{2}$ emissions, mainly from fossil fuel combustion, are projected to grow $40-110 \%$ between 2000 and 2030 (IPCC, 2007).

The electricity sector can play an important role in the reduction of anthropogenic GHG emissions. Around $40 \%$ of global GHG emissions fall on the electricity sector (Wheeler and Ummel, 2008; Manne and Richels, 1997). Today, the electricity system is mainly fossil-fuel based and centralized while power transmission and energy storage play a minor role. Regarding the considerable contribution of the power sector, substantial changes must be made in its present structure. Promotion of low emitting or emission-free technologies is of high priority to meet the proposed emissions reduction targets and to deal with the scarcity of fossil fuel resources. Projections of the global energy mix in integrated assessment models show that within the coming 
century a significant share of renewable energies is required to achieve stabilization targets of 450 and 400 ppm $\mathrm{CO}_{2}$-eq; there, mostly solar and wind energy are proposed as well as biomass as promising energy resources (van Vuuren et al., 2009).

The potential for reducing $\mathrm{CO}_{2}$ emissions in the long term has been evaluated in various studies, by focusing on national electricity generation systems (Heitman and Hamacher, 2009; Mathur et al., 2003). In Heitman and Hamacher (2009), the maximum feasible abatement in the German electricity generation system of 2030 has been determined, applying the German electricity system model. Influence of the carbon price and its uncertainty has been studied with stochastic parameterization of the specified planning tool based on stochastic linear programming. A study has been performed by Mathur et al. (2003) with applying the energy planning tool MARKAL to simulate the Indian power sector over a time horizon from 2000 to 2025 . The results show that besides hydro power, wind energy is an alternative solution, which becomes more and more attractive with the introduction of carbon taxes, while photovoltaic systems with the considered characteristics do not have any chance for large-scale penetration.

While the issue of long-term technological change has a high priority, short-term effects, caused by the internalization of emissions costs in an existing fleet of generation plants, may not be ignored. This concerns the influences on $\mathrm{CO}_{2}$ emissions before an optimal mix of low emitting power generation technologies could be brought online. In the short run, the demand for electricity would be met at the lowest cost by re-dispatching the existing generation units according to their marginal costs, which has risen by the $\mathrm{CO}_{2}$-price. Short-term effects of 
imposing prices on $\mathrm{CO}_{2}$-emissions of the U.S electric generators have been studied in Newcomer et al. (2008). A comprehensive study of the short-term abatement in the European power sector has been conducted in (Delarue, 2009).

In this paper, the focus is laid on both of the specified time horizons, which are relevant for studying systematic influences on $\mathrm{CO}_{2}$ emissions of the power system. Regarding the concern about the contribution of all parts of the world in an international movement towards an emission free electricity supply system, it is relevant to study this issue on the world-wide scale. Possible influences on the $\mathrm{CO}_{2}$ emissions abatement and the $\mathrm{CO}_{2}$-price are studied by applying a linear investment and production optimization model of the global electricity generation system. While the potential for reducing $\mathrm{CO}_{2}$ emissions in the short term is evaluated, long-term abatement in the power sector and required structural adaptations are studied. A special focus is laid on the influences caused by the integration of Fluctuating Renewable Energy Sources (FRES), i.e. solar and wind energy, and the role of an ideal global grid.

The paper proceeds as follows. In section two, the model used to optimize the global electricity generation system is described. Section three elaborates the calibration of this optimization model according to the actual power generation and emissions data of the year 2000 , before a carbon price existed in any part of the world. The $\mathrm{CO}_{2}$ emissions abatement that would be achieved if there was an internalization of emissions costs in all countries in 2006 is estimated in section 4.1. In section 4.2, interactions of different factors, influencing $\mathrm{CO}_{2}$ emissions of the power system, are studied. Section 4.3 focuses on the new investments, required to satisfy long-term emissions reduction targets; influence 
of the possibility for extension of solar and wind power and the role of international electricity exchange are investigated. In the last part conclusions are drawn.

\section{Model Description}

In this paper, a global, multi-regional electricity system investment planning model is applied (Aboumahboub et al., 2010); it has been developed based on the linear programming optimization method applying the General Algebraic Modeling System (GAMS) software package (Rosenthal, 2008). The model is an extension of the German electricity system model (Heitman and Hamacher, 2009).

Optimization can be performed over a one-year period with an hourly temporal resolution. The simulation methodology is adequate to properly mimic geographical dependencies of energy supply and demand as well as short-term and seasonal variations of the electricity produced from FRES and of the electricity load. The model is able to mimic complex interactions of system components within a multi-regional, interconnected electricity supply system by representing technical restrictions of power plants on a technology level, temporal fluctuations and geographical dependencies of renewable energy sources, and exogenously imposed boundary conditions.

New investments in power generation, storage and inter-regional power transmission are optimized by considering the development of electricity demand, variability of FRES, and influences of framework conditions. The power produced by each of the power plant technologies, inter-zonal energy flows, $\mathrm{CO}_{2}$ emissions, and marginal price of electricity in perfect competitive markets are determined for each region at every hour of the simulation period. 
The cost of avoiding one ton of $\mathrm{CO}_{2}$ - i.e. marginal price of $\mathrm{CO}_{2}$ emissions - is also concluded from the optimization model.

The model covers a worldwide scale. The spatial resolution of the model is at first limited according to the geographical detail of the used meteorological data. Additionally, the temporal resolution and geographical accuracy are limited according to the accessible computation power and due to the long calculation time. The global model, which is applied in this paper, comprises 50 regions. The model regions are determined not only based on the political borders but also according to the geographic distribution of electricity demand and renewable supply. The zonal configuration of the model is represented in Table A.1.

In the following, formulation of the model is described. Table B.1 gives an overview of the used symbols.

\subsection{Model Formulation}

Total system costs serve as objective function and are given in (1). It is composed of total investment, fixed and variable operation costs of all power plants, inter-regional power transmission lines, and energy storage facilities. The last sum represents the emissions costs. From a macro-economic perspective, minimization of overall costs, which corresponds to maximization of producers' and consumers' surplus, defines an ideal operation of the energy system through a central planner. 


$$
\begin{aligned}
& z=\sum_{x}\left\{\sum_{i \in \operatorname{Pr} P G}\left[k_{i}^{I n v} \cdot C N_{i}(x)+k_{i}^{F i x} \cdot C_{i}(x)+\sum_{t} k_{i}^{\text {Var }} \cdot E_{i}^{i n}(x, t) \cdot w(t)\right]\right. \\
& +\sum_{y} \sum_{i \in \operatorname{Pr} T r}\left[\frac{1}{2} r(x, y) \cdot\left(k_{i}^{I n v} \cdot \operatorname{CNTr}_{i}(x, y)+k_{i}^{F i x} \cdot \operatorname{CTr}_{i}(x, y)\right)+\sum_{t} k_{i}^{\operatorname{Var}} \cdot \operatorname{ETr}_{i}^{i n}(x, y, t) \cdot w(t)\right] \\
& +\sum_{i \in \operatorname{Pr} S t o}\left[k_{i}^{\text {Inv }} \cdot \operatorname{CNStin}_{i}(x)+k_{i}^{\text {Fix }} \cdot \operatorname{CStin}_{i}(x)+\sum_{t} k_{i}^{\text {Var }} \cdot \operatorname{ESt}_{i}^{i n}(x, t) \cdot w(t)\right] \\
& +\sum_{i \in \operatorname{Pr} S t o}\left[k_{i}^{\text {Inv }} \cdot \text { CNStout }_{i}(x)+k_{i}^{\text {Fix }} \cdot \text { CStout }_{i}(x)+\sum_{t} k_{i}^{\text {Var }} \cdot \operatorname{ESt}_{i}^{\text {out }}(x, t) \cdot w(t)\right] \\
& +\sum_{i \in \operatorname{Pr} S t o}\left[k_{i}^{I n v} \cdot \operatorname{CNSt}_{i}(x)+k_{i}^{F i x} \cdot \operatorname{CSt}_{i}(x)+\sum_{t} k_{i}^{\text {Var }} \cdot \operatorname{EStTot}_{i}(x, t)\right] \\
& \left.+\sum_{i \in \operatorname{Pr} P G} \sum_{t}\left[E_{i}^{i n}(x, t) \cdot k e m f_{i} \cdot k C O 2 e \cdot w(t)\right]\right\}
\end{aligned}
$$

Minimization of overall system costs is subject to restrictive equations, describing the energy system. The demand satisfaction constraint, given in (2), certifies that at each hour, the total power produced by all power plants available at each region plus the import-export balance and storage output minus the power that hydro pumped-storage units need for pumping is equal to the electricity demand of that region at the corresponding hour. Overproduction is allowed when there is excess production from FRES.

$$
\begin{aligned}
& \sum_{i \in \operatorname{Pr} P G} E_{i}^{\text {out }}(x, t)+\sum_{y} \sum_{i \in \operatorname{Pr} T r}\left[\operatorname{ETr}_{i}^{\text {out }}(x, y, t)-\operatorname{ETr}_{i}^{\text {in }}(x, y, t)\right] \\
& +\sum_{i \in \operatorname{Pr} S t o}\left[E S t_{i}^{\text {out }}(x, t) \cdot \eta_{i}^{\text {out }}-E S t_{i}^{\text {in }}(x, t) \cdot \eta_{i}^{\text {in }}\right] \geq \operatorname{dem}(x, t)
\end{aligned}
$$

According to (3), the total capacity of each power plant technology is equal to the previously installed capacity, given as a parameter, plus the newly installed capacity, which is optimized.

$$
C_{i}(x)=C 0_{i}(x)+C N_{i}(x)
$$

The capacity constraint, given in (4), certifies that the total installed capacity of each generation technology at each region is lower than the associated upper limit. The total capacity of each renewable technology is restricted according to 
the corresponding technical potential (see section 2.2). Eq. (5) represents the losses, occurring through energy conversion processes.

$$
\begin{aligned}
& C_{i}(x) \leq c U p_{i}(x) \\
& E_{i}^{\text {out }}(x, t)=E_{i}^{\text {in }}(x, t) \cdot \eta_{i}
\end{aligned}
$$

The energy-capacity balance for dispatchable power plants and nondispatchable renewable power plants is given in (6) and (7), respectively. It is assumed that a conventional power plant has a maximal output at each hour, which is equal to its rated output multiplied by the standard availability factor. The availability factor $(A V F)$ is a technology-specific parameter to downscale the capacity of a power plant due to periodic maintenance and forced outages. However, for non-controllable energy sources, additionally, a time- and regionspecific capacity factor (Supim) is used to determine the available energy from weather dependent renewable sources such as solar, wind, and hydro at every hour of the simulation period.

$$
\begin{aligned}
& E_{i}^{\text {out }}(x, t) \leq C_{i}(x) \cdot A V F_{i} \\
& E_{i}^{\text {out }}(x, t)=C_{i}(x) \cdot A F_{i} \cdot \operatorname{Supim}_{i}(x, t)
\end{aligned}
$$

Technical constraints of dispatchable power plants are respected at a technology-aggregated level. Technology ramping constraints are represented in (8).

$$
\left|E_{i}^{\text {out }}(x, t)-E_{i}^{\text {out }}(x, t-1)\right| \leq \operatorname{ramp}_{i} \cdot C_{i}(x)
$$

The following constraints limit the maximum input, output, and stored energy according to the total available capacity. 


$$
\begin{aligned}
& \operatorname{ESt}_{i}^{\text {in }}(x, t) \leq \operatorname{CStin}_{i}(x) \\
& \operatorname{ESt}_{i}^{\text {out }}(x, t) \leq \operatorname{CStout~}_{i}(x) \\
& \operatorname{EStTot}_{i}(x, t) \leq \operatorname{CSt}_{i}(x)
\end{aligned}
$$

The balance equation, given in (12), defines the energy content of the reservoir at each time step by taking into account the output power and energy inflow for the pump processes.

$$
E S t_{i}(x, t)=E S t_{i}(x, t-1)+E S t_{i}^{\text {in }}(x, t) \cdot \eta_{i}^{\text {in }}-\frac{E S t_{i}^{\text {out }}(x, t)}{\eta_{i}^{\text {out }}}
$$

The inter-zonal energy transport lines are modeled as trade-based interconnections. Eq. (13) limits the transport capacity between model regions according to the given upper limit. The next restriction limits the inter-zonal energy flow according to the total available capacity. Eq. (15) represents the energy balance by taking into account the transport losses.

$$
\begin{gathered}
\operatorname{CTr}_{i}(x, y) \leq c \operatorname{UpTr}_{i}(x, y) \\
\operatorname{ETr}_{i}^{\text {out }}(x, y, t) \leq \operatorname{CTr}_{i}(x, y) \\
. . \operatorname{ETr}_{i}^{\text {out }}(x, y, t)=\operatorname{ETr}_{i}^{\text {in }}(x, y, t) .\left(1-\operatorname{Tr}_{i} . r(x, y)\right)
\end{gathered}
$$

The $\mathrm{CO}_{2}$ emissions constraint is given in (16). Total $\mathrm{CO}_{2}$ emitted from all power plants must be lower than the given $\mathrm{CO}_{2}$-limit. According to the property of primal/dual systems in linear programming (Dantzig, 1997), the dual variable of Eq. (16) represents how much the system costs would increase if $\mathrm{CO}_{2}$ emissions would be mitigated by another one unit. This determines the $\mathrm{CO}_{2}$ price for the given level of abatement. 


$$
\sum_{x} \sum_{i \in \operatorname{Pr} P G} \sum_{t} E_{i}^{i n}(x, t) \cdot k e m f_{i} \cdot w(t) \leq \operatorname{co} 2 U p
$$

\subsection{Model Database}

The satellite data of Surface Solar Irradiation Data Set (SSIDS) have been used here to determine the geographic distribution of hourly variations of available solar energy (Bishop, 2000). To evaluate the variable output power from wind turbines in on- and off- shore sites on an hourly basis, the modeled wind speeds of World Wind Atlas (WWA, 2009) have been applied. The transformation from wind velocity to active power output has been made applying the multi-turbine power curve approach (Norgaard and Holttinen, 2004; VESTAS, 2009).

Total capacity of renewable power plants that can be installed at each model region is limited according to the geographical potential. This has been determined based on the detailed analyses of global technical potential of wind energy and solar thermal electricity production (Aboumahboub et al., 2010; Brückl, 2005; Tzscheutschler, 2005).

Geographically aggregated projections of the global electricity demand over the time period from 2010 to 2100 based on the B2 scenario of Intergovernmental Panel on Climate Change (IPCC) has been rescaled according to the spatial distribution of population (IIASA GGI, 2009). The hourly electrical load profile of each region has been determined using the linear combination of normalized load curves of comprising countries (Elerging OÜ, 2009; ENTSOE, 2009; UK National Grid, 2009; Zickermann, 2005).

The Capacity of operating power plants has been determined using the UDI World Electric Power Plants Data Base (UDI WEPP, 2010). To reduce the complexity, power plants have been aggregated according to the main fuel and 
technology type. The decommissioned capacity of power plants over future time periods has been evaluated assuming a technology-specific lifetime (Roth and Kuhn, 2008).

The global energy production database, Carbon Monitoring for Action (CARMA) (Wheeler and Ummel, 2008), is a massive database, containing information about the carbon emissions of over 50000 power plants and 4000 power companies worldwide. Ultimately, through the linkage of the UDI WEPP to the CARMA database on a power plant basis, localization and mapping of existing power plants to model regions is realized.

\section{Model Validation}

In its standard form, the model is based on a number of assumptions that may be regarded as unrealistic according to the real power generation systems. For instance, it is assumed that the prices paid for fossil fuels and used for dispatch decisions are equal through all regions. These are annual average prices in international markets. However, in reality, they vary considerably through the year and different countries. Furthermore, techno-economic parameters of each power plant technology are assumed to be uniform through all regions. The maximum production from conventional power plants is restricted by the standard availability factor (see Eq. (6)) while contract considerations are not taken into account in dispatch decisions. Moreover, it is assumed that wholesale markets are completely liberalized.

While these deviations from real conditions are typical for modeling purposes, the question, whether the model can properly mimic the behavior of an actual electricity generation system, must be addressed. Question remains also 
concerning the consequent effect of the deviation from an actual condition on the estimation of $\mathrm{CO}_{2}$ emissions abatement in response to a $\mathrm{CO}_{2}$-price.

The aim of this part is thus to examine if the applied methodology and the used database are capable of representing an actual mix of produced power. The year 2000 has been chosen for calibration as it is the latest period, for which all the required datasets were available at the time of writing. It also represents the time point, when the $\mathrm{CO}_{2}$-price did not exist in any part of the world.

At first, the non-calibrated model is run using the power plant stock as it existed in year 2000 along with the electricity demand, given in (EIA, 2010); standard availabilities of power plants have been taken from (VGB POWER TECH, 2008); annual average fuel prices in international markets are obtained from (IEA, 2002).

Net transfer capacities (NTC) from (ENTSOE, 2009) are applied to represent the existing power transmission interconnections between the regions in Europe. Due to the lack of accurate and sufficient information about the capacity of power transmission lines between model regions outside Europe, inter-zonal electricity exchange is not included in the calibration or restricted by implementing a low upper capacity boundary. Thirteen weeks are simulated to represent the whole year. Techno-economic parameters of power plants and fuel prices are represented in Table C.1.

The non-calibrated model's output is compared with the real power production mix of year 2000 in Fig. 1. Comparison of the aggregated power production in Fig. 1.a shows that the simulation results are very close to real estimates. However, total power production from the optimization model is $2 \%$ lower than 
the real produced power. The deviation is nearly zero for Europe; however, it reaches to $-4 \%$ for Asia.

In the used historical data, total net electricity consumption is lower than the total net electricity generation. The explanation arises from the fact that energy losses, occurring due to reserve power production, and power transmission and distribution losses are not included in the net electricity consumption. The cost minimization model, thus, matches the total produced power to the net electricity demand while it only considers inter-regional power transmission losses. Therefore, in addition to energy losses, resulting from reserve power production, the energy losses, occurring through intra-regional power transmission and distribution, are not taken into account due to the coarse geographical resolution of the model. Furthermore, the deviation is higher in regions outside Europe due to the lack of accurate historical data for bilateral electricity exchange and the power transmission capacities between those regions.

By comparing the power production from the optimization model, which is categorized into power plant technologies, with the actual power generation mix, higher deviations can be noticed (see Fig. 1.b). Finally, it is concluded that there exists a general tendency: the model decides to use more coal and lignite than was actually utilized while it underestimates the usage of natural gas and oil. This tendency exists for all continents; however, the deviation is very low in Europe followed by America.

One influential factor is the ratio of the domestic price of natural gas and coal to the international market price of crude oil. The domestic prices that differ from international market values, used in the simulation, may lead to such deviations. 
Another influencing factor is the actual lower availability of coal- and lignitefired plants than the assumed availability factors. Lower availability can be caused by technical restrictions and/or lack of fuel supply.

Furthermore, according to the applied deterministic approach, forecasting errors of electricity load and unforeseen fluctuations of wind power plants are not taken into account. Moreover, the model respects ramp rates of power plants at a technology level as detailed technical restrictions of power generation units can not be directly formulated within a non-mixed integer problem (Delarue, 2009). Thus, base- and mid- load technologies are considered to be more flexible than real generation plants. As a result, the model uses the cheapest available technology in dispatch decisions, and the contribution of flexible, peak and high peak generators is underestimated. 


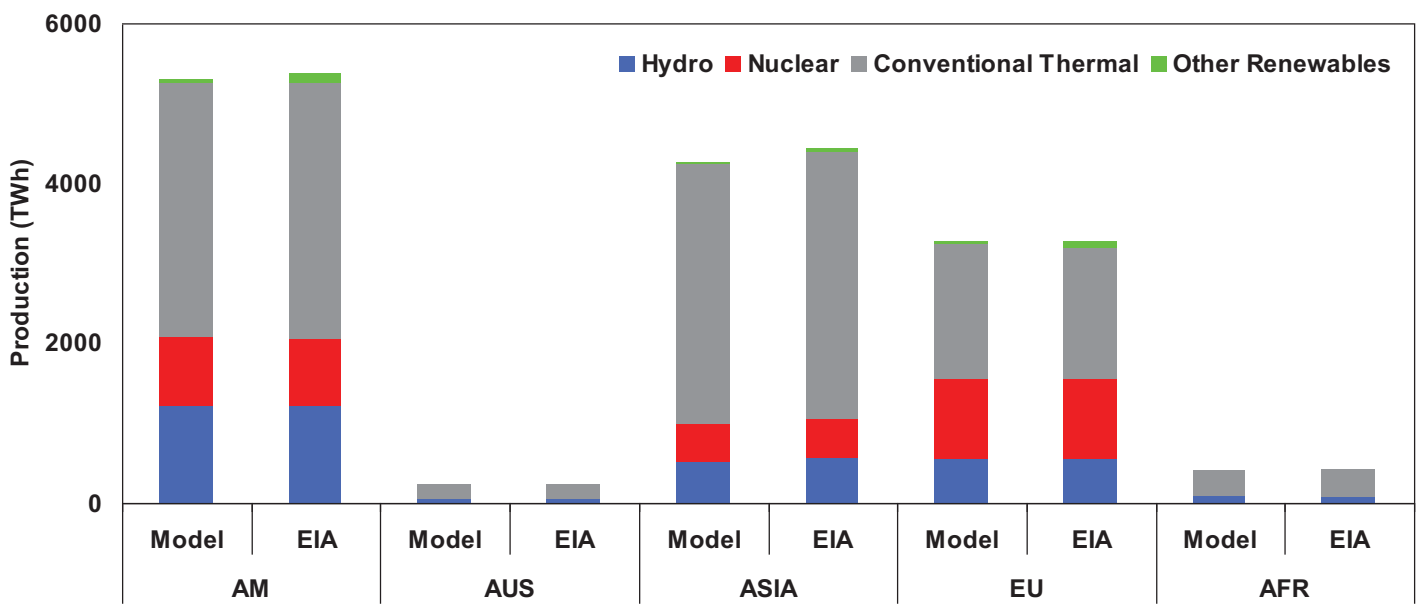

(a)

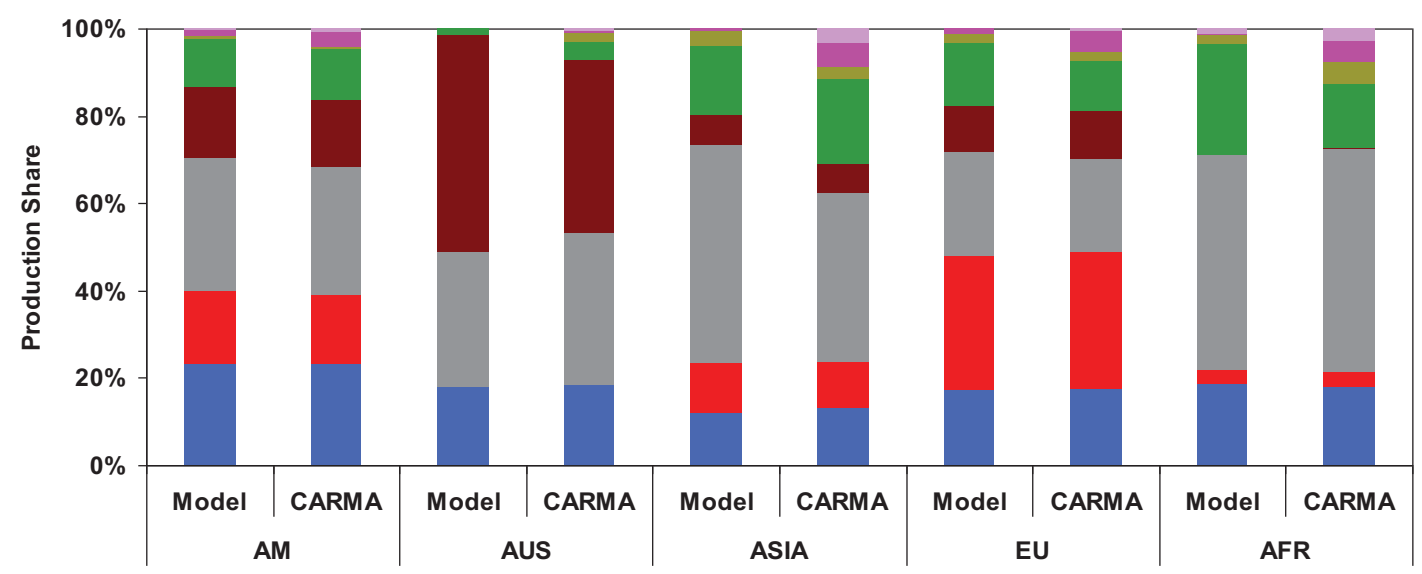

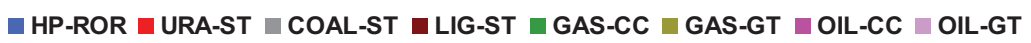

(b)

Fig.1: Model results vs. real net electricity generation of year 2000 (a) Comparison with EIA; (b) Comparison with CARMA

To minimize the deviation of the results, obtained from the optimization model, from the real power production mix of the year 2000, a sensitivity study is performed by varying the availabilities of power plants and fuel prices. In order to focus on the generation from fossil fuels, which are the sources of emissions, the power produced from biomass, hydro, solar, and wind are matched to real values as closely as possible. A calibrated model is then developed, which yields the least deviation from the real estimates. One main correction in developing a calibrated model is to introduce region-specific availability factors for nuclear power plants to match the power production to the real produced 
electricity by nuclear power plants based on data from (EIA, 2010). Moreover, availability factors of coal- and lignite- fired power plants are reduced, and factors are introduced to change fuel price ratios in specific regions. Furthermore, in specific regions, the total annual electricity demand is scaled to compensate for power transmission and distribution losses and match the total power production to the actual net electricity generation, as it is given in (EIA, 2010).

As a measure of overall improvement, the Root Mean Square (RMS) of absolute differences between the results of the optimization model and the real values in terms of power generation per fuel per zone is minimized. Lower availability of coal- and lignite- fired power plants in the calibrated model compared to the base model leads to their replacement with gas combine-cycle and oil-fired plants. Reduction of RMS clarifies improvement of the results through the calibration; this factor is finally reduced by $54 \%$ at global scale (see Fig. 2). 


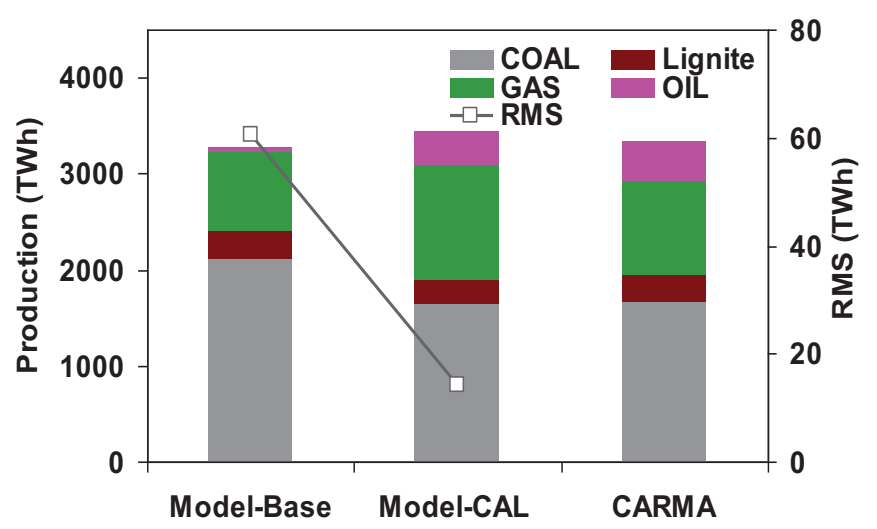

(a)

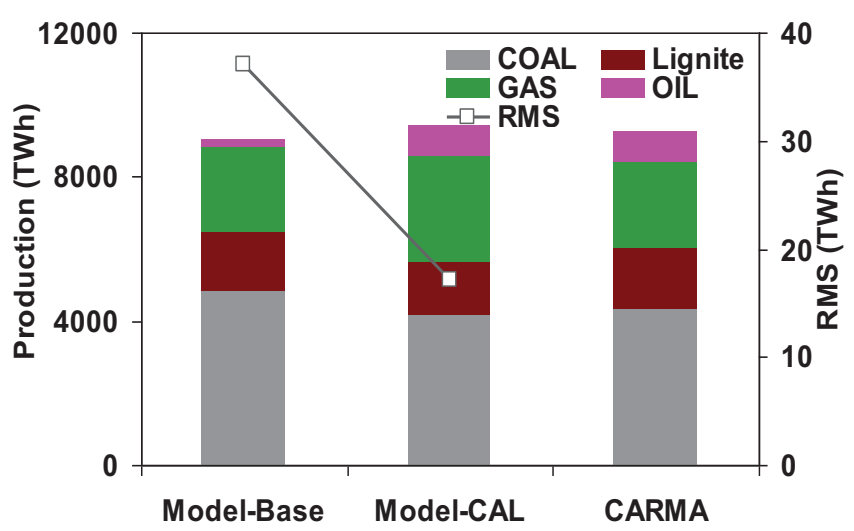

(b)

Fig.2: Power generation per fuel type in non-calibrated model (Model-Base) and calibrated model (Model-CAL) vs. real net generation of year 2000 (a) Asia (b) World

Total $\mathrm{CO}_{2}$ emissions, obtained from the optimization model, are in good accordance with real estimates. According to an approximation provided in (Wheeler and Ummel, 2008), $\mathrm{CO}_{2}$ emissions from the power sector were 9395 million tons through the year 2000. Applying the calibrated model, total $\mathrm{CO}_{2}$ emissions of year 2000 reach to 9750 million tons, which is only $4 \%$ higher than the estimation given in (Wheeler and Ummel, 2008). The non-calibrated model approximates the emissions at $5 \%$ above the referenced value. 


\section{Results}

\subsection{Potential for Short-term $\mathrm{CO}_{2}$ Emissions Abatement}

Possible influences on $\mathrm{CO}_{2}$ emissions of the global electricity sector in a shortterm perspective and the influence of model calibration are studied in this subsection. The model is applied to estimate the total abatement that would be achieved if a $\mathrm{CO}_{2}$-price existed in all countries in year 2006. This year has been chosen as it is the most recent year after internalization of emissions costs in European countries, for which all the required data were available at global scale at the time of writing.

The model based on standard assumptions and the calibrated version are run using the power generation capacity of year 2006, as it is given in (UDI WEPP, 2009), along with the electricity demand and fuel prices based on data from (EIA, 2010; IEA, 2006). For this purpose, in the calibrated version, only the adjusted availability factors are taken into account while the fuel costs are assumed at annual average prices in international markets and are uniform through all regions. This can be explained as the deviations of domestic fuel prices from international market prices, which have been estimated for the year 2000, can not be assumed to remain valid in year 2006.

At first, the $\mathrm{CO}_{2}$-price is assumed at zero in all regions to estimate the emissions that would occur without its existence. This is used as a basis to approximate the possible reduction of emissions in response to a global $\mathrm{CO}_{2-}$ price. In other simulation runs, the average $\mathrm{CO}_{2}$-price of the European power sector in year 2006 (18 €/ton) is used as a uniform price in all regions. The abatement is determined by taking the difference between the runs that incorporate the carbon price and the base case with a zero $\mathrm{CO}_{2}$-price. 
If a zero $\mathrm{CO}_{2}$-price existed in all countries, total $\mathrm{CO}_{2}$ emissions of the year 2006 would reach to 12445 million tons according to the results of the calibrated model. Based on the results of the non-calibrated model and the potential for emissions reduction, estimated by the calibrated version, an upper and a lower bound of 1165 and 625 million tons can be proposed for the abatement that would be achieved through fuel switching in response to a global carbon price of $18 € /$ ton in year 2006 . The non-calibrated model overestimates the emissions and achievable abatement due to the higher utilization of existing coal- and lignite- fired power plants than in reality (see section 3). However, the calibrated model approximates a minimum level for the abatement potential. Downward adjustment of the availability of coal- and lignite- fired plants in the calibrated version leads to the reduction of emissions and achievable abatement.

\subsection{Topology of Abatement - Complex Interaction of Influential Factors}

Here, interaction of different influential factors of $\mathrm{CO}_{2}$ emissions is studied in detail. These include the system load, fuel prices, and the share of renewable energies in addition to the $\mathrm{CO}_{2}$-price.

\subsubsection{Scenario Setup}

An optimization is performed for a medium-term horizon, the year 2025. Thirteen weeks are simulated to represent the total year. Hourly variations of wind power capacity factor and solar irradiation are determined based on the meteorological data of the year 1993, given in (Bishop, 2000; WWA, 2009). The approach applied to estimate these parameters is described in (Aboumahboub et al., 2010). 
While in baseline scenario extension of renewable technologies is not allowed, in scenarios "WND-OPT" and "WND-OPT-CFH", extension of wind power at each region up to the technical potential is possible. The model chooses the most promising sites according to the wind power's investment costs, annual full load hours, temporal fluctuations and correlation with regional electrical load profiles as well as proximity to densely populated areas. The "WND-" scenarios differ in the applied time series of wind power capacity factor. The average wind power capacity factor is $20 \%$ and $25 \%$ in scenarios "WND-OPT" and "WNDOPT-CFH", respectively. This is due to the lower assumed cut-in wind speed for the transformation of wind velocity to active power output in preparation of the time series of wind power capacity factor for scenario "WND-OPT-CFH".

It is assumed that the nuclear power's operation time is restricted to 34 years for all regions; new investments are not allowed. Moreover, it is assumed that operating hydro power plants are not expandable. The new capacities of geothermal power plants are restricted according to the planned capacities, given in (UDI WEPP, 2010). Already installed capacities for power transmission and storage up to the year 2009 are set as upper capacity boundaries. A rather low $\mathrm{CO}_{2}$-price of $24 € /$ ton is used. Assumed techno-economic parameters of power plants and fuel prices are represented in Table D.1 and Table D.2. The investment costs are annualized using the economic lifetimes, given in Table D.1, and by assuming a discount rate of 5\%/a.

Fig. 3 shows the total generation capacity mix. The base case represents a coal-based system with nearly zero share of wind energy while this share reaches to $17 \%$ and $34 \%$ of the global electricity demand in scenarios "WND-OPT" and "WND-OPT-CFH", respectively. 


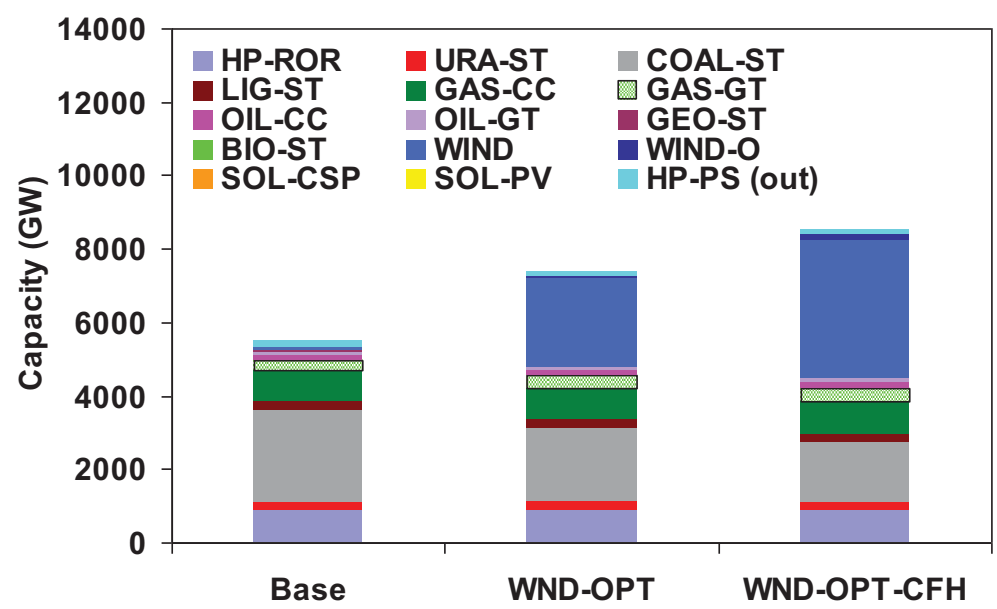

Fig.3 Optimal power generation capacity mix in scenarios "Base", "WND-OPT", and "WND-OPTCFH"

Fig. 4 compares the total installed capacity for wind power production in scenarios "WND-OPT" and "WND-OPT-CFH" with scenarios of the Global Wind Energy Council (GWEC, 2006). The scenario "Advanced 2030" with 20\% penetration share of wind power is the closest to the optimization results, obtained from the scenario "WND-OPT".

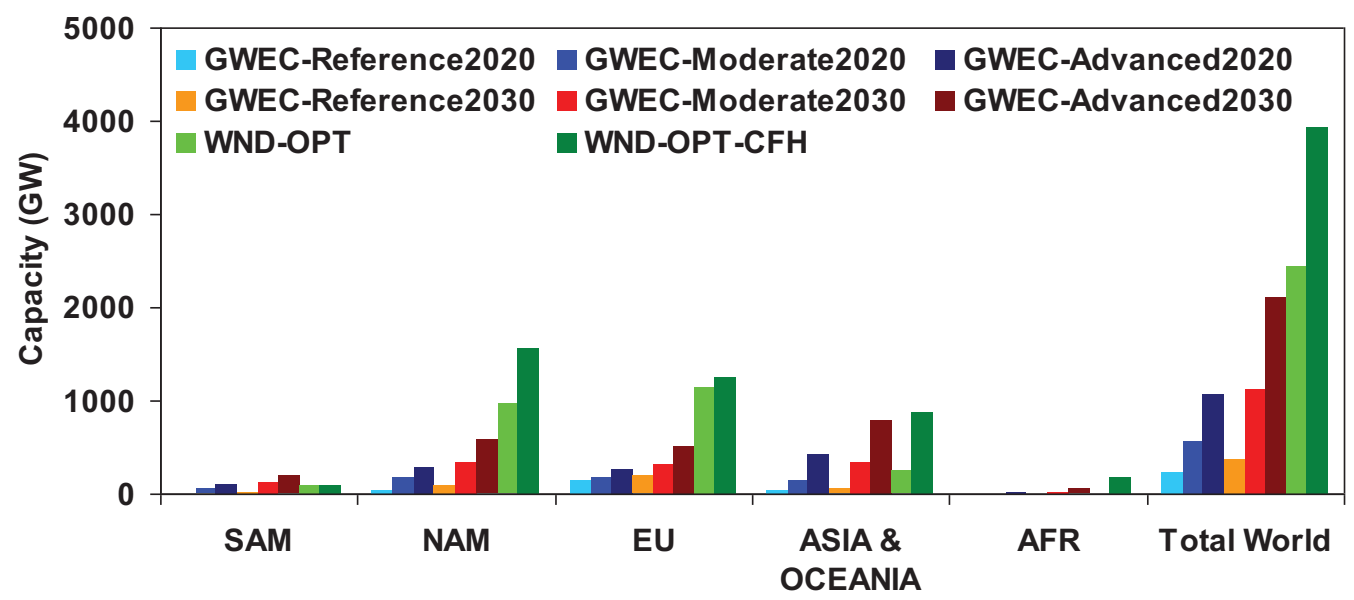

Fig.4 Total wind power capacity in scenarios "WNDOPT" and "WNDOPT-CFH" vs. Global Wind Energy Council scenarios

The optimal capacity of power plants obtained from the scenarios "Base" and "WND-OPT" is now used as a basis to represent two possible configurations of a medium-term global electricity system, differing in the integrated share of FRES. 


\subsubsection{Influence of Load and $\mathrm{CO}_{2}$-certificate price}

The capacity of power plants are now fixed at the optimal levels, obtained from the scenarios "Base" and "WND-OPT"; a sensitivity study is then performed, using the variation of $\mathrm{CO}_{2}$-price and fuel prices. In all cases, the $\mathrm{CO}_{2}$-price is increased from zero to $100 € /$ ton at intervals of $20 € /$ ton. Another influential factor is the ratio of the natural gas price or the oil price to the price of hard coal. However, at first, the focus is laid on the influence of hourly electricity load and the $\mathrm{CO}_{2}$-price; thus, constant fuel prices are used.

The residual load is identified as a main influencing factor of $\mathrm{CO}_{2}$ emissions. Higher load implies more energy production. The residual load - a part of load, not being covered by wind energy - must be satisfied with fossil energy, and, thus, correlates with hourly emissions. Fig. 5.a and Fig. 6.a show the dependency of hourly global emissions on hourly load at different $\mathrm{CO}_{2}$ prices.

The achieved abatement is determined by subtracting the $\mathrm{CO}_{2}$ emissions at each hour at a positive $\mathrm{CO}_{2}$-price from the $\mathrm{CO}_{2}$ emissions, occurring at the corresponding hour at the zero $\mathrm{CO}_{2}$-price. According to Fig. 5.b and Fig. 6.b, hourly abatement decreases with the residual load regardless of the $\mathrm{CO}_{2}$-price and the share of wind energy. In response to a $\mathrm{CO}_{2}$-price fuel switching occurs; the possibility for fuel switching with constant fossil fuel prices depends on the available capacity of low emitting generation plants. At lower levels of load, in the coal-based system of baseline scenario and in an electricity generation system with a moderate share of wind energy, obtained from the "WND-OPT", coal-fired plants operate at base load; gas-fired plants are available for substitution at higher $\mathrm{CO}_{2}$ prices. However, at peak load, power plants mostly operate at their full installed capacity; thus, the potential for fuel switching 
diminishes. Due to the lower utilization of coal-fired plants in scenario "WND-OPT" as compared to the base case, the potential for fuel switching is reduced at any given $\mathrm{CO}_{2}$-price. This effect is more evident at lower levels of load.

Furthermore, it is concluded that a $\mathrm{CO}_{2}$-price of $20-40 € /$ ton is not adequately high to encourage a significant abatement in the considered power systems. Limited fuel switching occurs only at lower levels of load. At a higher $\mathrm{CO}_{2}$-price of $60 € /$ ton, a significant level of abatement is achieved. However, saturation effects occur afterwards, and further changes at higher $\mathrm{CO}_{2}$ prices (80-100 $€ /$ ton) are insignificant.

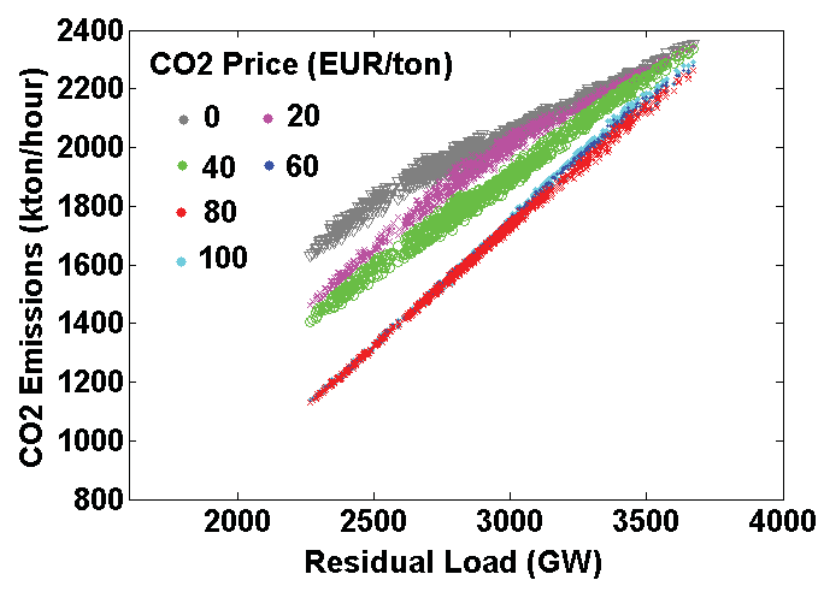

(a)

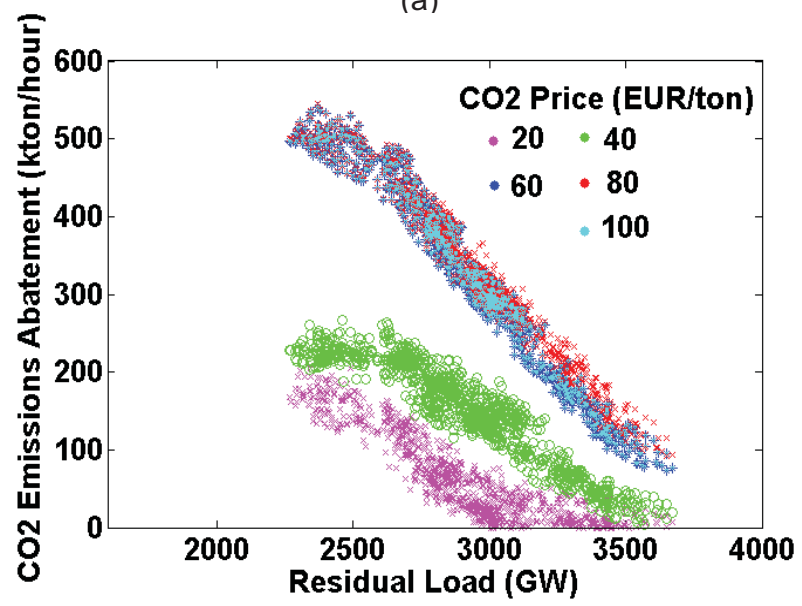

(b)

Fig.5: Influence of load and $\mathrm{CO}_{2}$-price on $\mathrm{CO}_{2}$ emissions in scenario "Base" (a) Sorted hourly $\mathrm{CO}_{2}$ emissions summed over all regions; (b) Corresponding abatement 


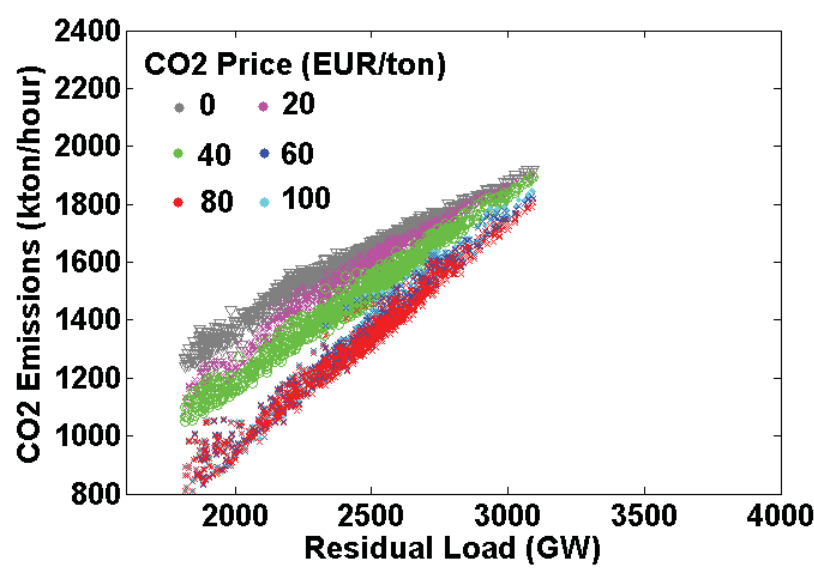

(a)

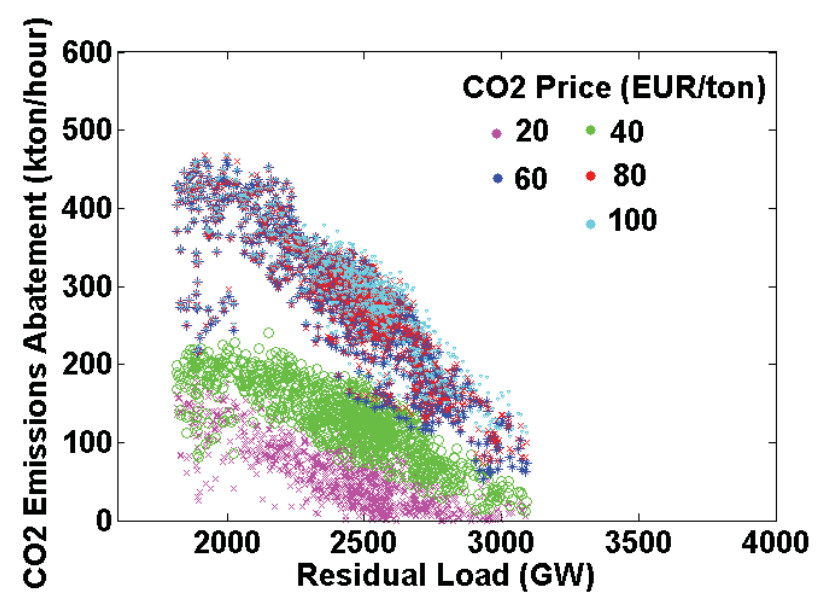

(b)

Fig.6: Influence of load and $\mathrm{CO}_{2}$-price on $\mathrm{CO}_{2}$ emissions in scenario "WND-OPT" (a) Sorted hourly $\mathrm{CO}_{2}$ emissions summed over all regions; (b) Corresponding abatement

\subsubsection{Fuel Price Effects}

In order to clarify the absolute impact of fuel prices, variation of load through the year is initially excluded from the results.

Fig. 7 and Fig. 8 show the $\mathrm{CO}_{2}$ emissions and the corresponding abatement at a typical winter peak hour over a range of gas to coal price ratios. At a zero $\mathrm{CO}_{2}$-price, when the gas price is reduced to zero, hourly $\mathrm{CO}_{2}$ emissions reach to around 2000 and 1500 ktons in scenarios "Base" and "WND-OPT", respectively (see Fig. 7.a and Fig. 8.a). If the gas price rises, the power produced from coal substitutes the power generation from natural gas. Correspondingly, $\mathrm{CO}_{2}$ emissions rise and at a gas to coal price ratio of 2 reach 
to a peak of around 2150 and 1600 ktons in scenarios "Base" and "WND-OPT", respectively. According to Fig. 7.a and Fig. 8.a, when increasing the $\mathrm{CO}_{2}$-price, lines are pushed down, and the peak of abatement is shifted to the right. At any given $\mathrm{CO}_{2}$-price, when increasing the gas price, less efficient gas-fired units are initially replaced by the most efficient coal-fired power plants. At higher gas prices, it is economic to replace even the most efficient combined-cycle plants with lignite-fired units. At higher $\mathrm{CO}_{2}$ prices, the capacity utilization of coal-fired units is reduced due to the higher emissions costs, and gas combined-cycle plants mainly operate at base load. Hence, switching opportunities are exhausted at higher gas prices.

The abatement, achieved in response to a $\mathrm{CO}_{2}$-price, is calculated by taking the difference between the emissions at the corresponding $\mathrm{CO}_{2}$-price and the emissions, occurring at a zero $\mathrm{CO}_{2}$-price. Fig. 7.b and Fig. 8.b show the corresponding abatement in scenarios "Base" and "WND-OPT", respectively. At a low gas price, there are very few switching opportunities because gas-fired plants have been already committed as base load generators. Thus, all the abatement lines reach their minimum at a gas price of zero. While increasing the gas price, more coal-fired capacity is committed at the expense of natural gas until the technical limits are reached. This creates opportunities for fuel switching, which can be utilized with increasing the $\mathrm{CO}_{2}$-price. Hence, the abatement rises when increasing the gas price. However, at any given $\mathrm{CO}_{2}-$ price, there is a gas to coal price ratio, which is adequately high to make further switching in favor of gas economically unattractive. From this point onward, more switching opportunities are continuously created by increasing the gas price until the technical limits are reached. However, at the given $\mathrm{CO}_{2}$-price, further commissioning of lower emitting gas-fired units at the expense of coal- 
fired plants is economically unattractive. Therefore, all the abatement lines reach a peak and fall afterwards. At higher $\mathrm{CO}_{2}$ prices, the peak of abatement is higher and occurs mainly at a gas to coal price ratio of 2 .

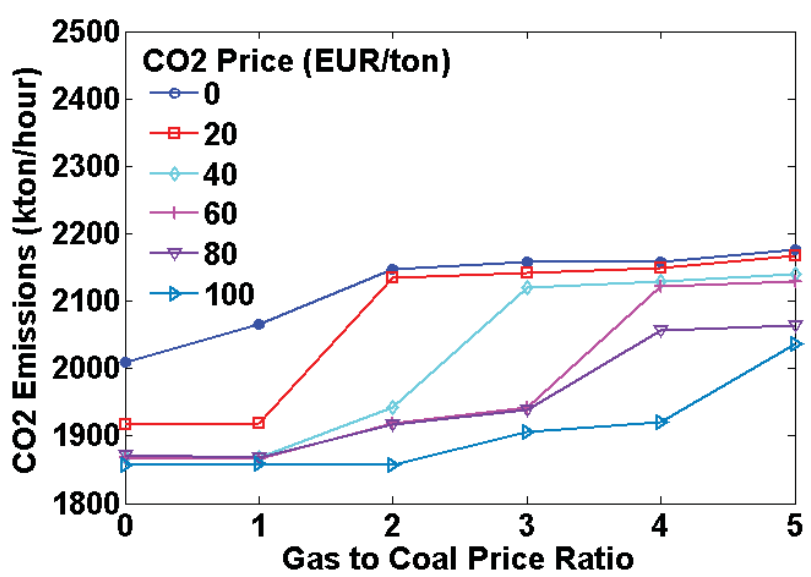

(a)

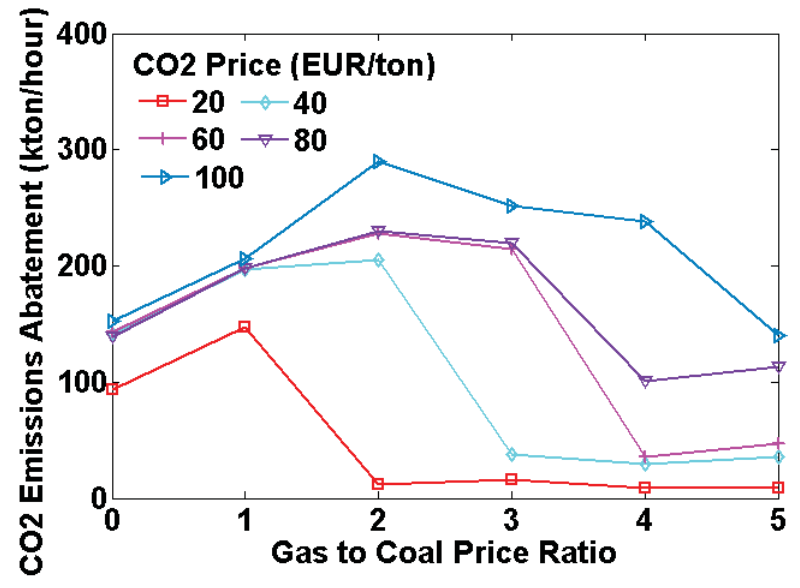

(b)

Fig.7 Influence of $\mathrm{CO}_{2}$-price and fuel price on $\mathrm{CO}_{2}$ emissions at a typical winter peak hour in scenario "Base" (a) $\mathrm{CO}_{2}$ emissions summed over all regions; (b) Corresponding abatement 


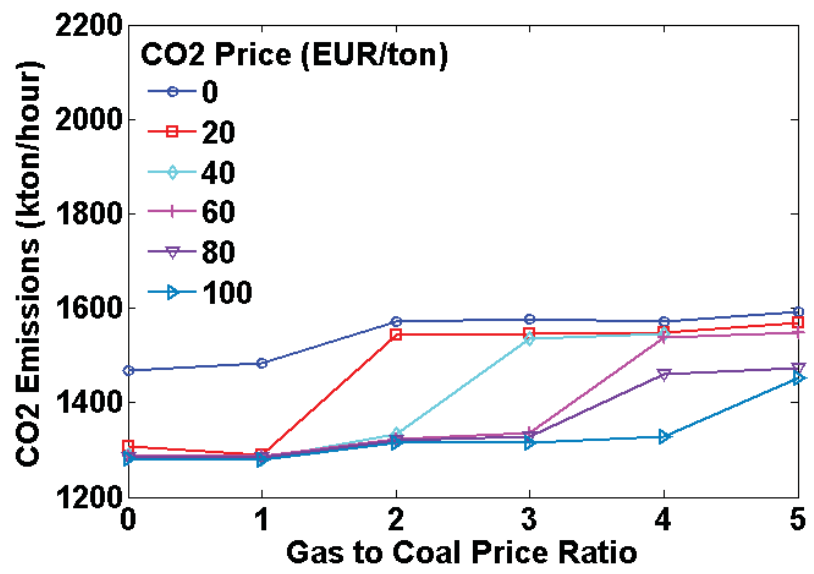

(a)

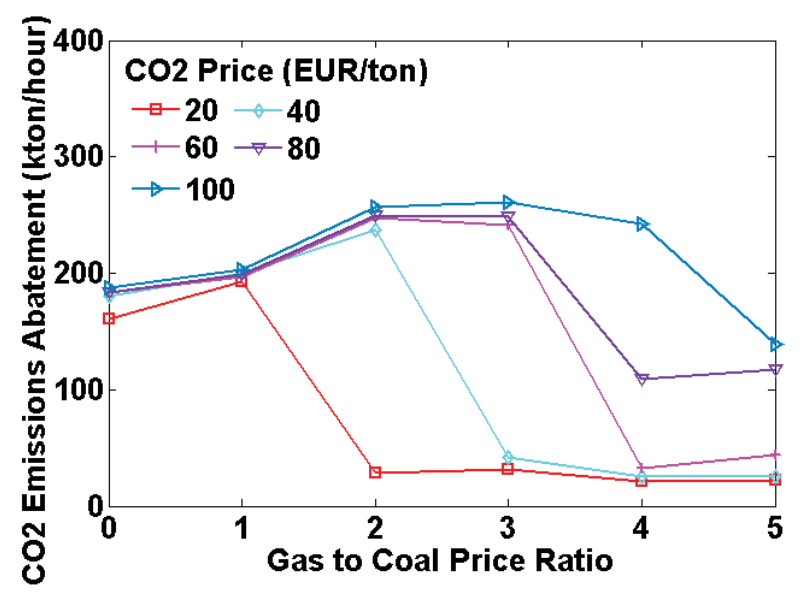

(b)

Fig.8: Influence of $\mathrm{CO}_{2}$-price and fuel price on $\mathrm{CO}_{2}$ emissions at a typical winter peak hour in scenario "WND-OPT" (a) $\mathrm{CO}_{2}$ emissions summed over all regions; (b) Corresponding abatement

The $\mathrm{CO}_{2}$ emissions are changed due to the variation of the capacity utilization of fossil-fired power plants. This is caused by variation of the $\mathrm{CO}_{2}$-price and fuel costs. In order to clarify underlying effects, imposed by price variations, and making a comparison between the base case and the "WND-OPT" scenario, capacity utilization of fossil-fired plants is illustrated in Fig. 9 and Fig. 10 for a typical winter peak hour as in Fig. 7 and Fig. 8. 


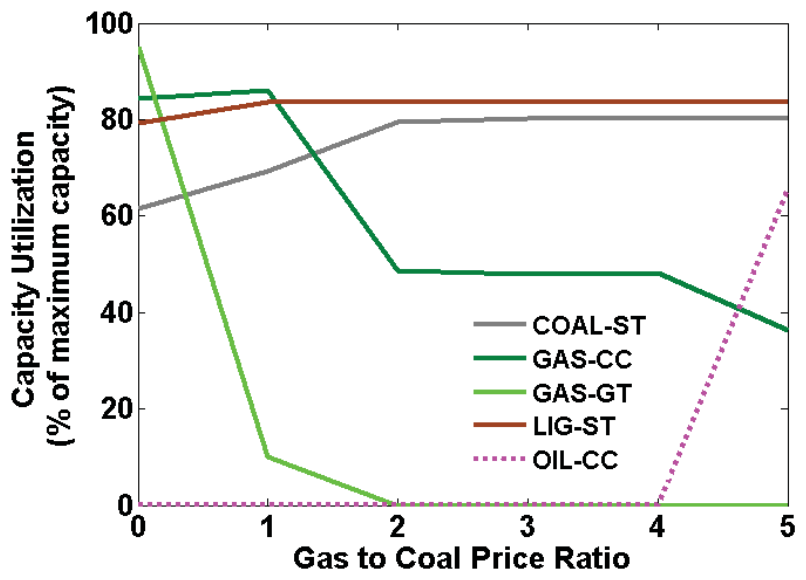

(a)

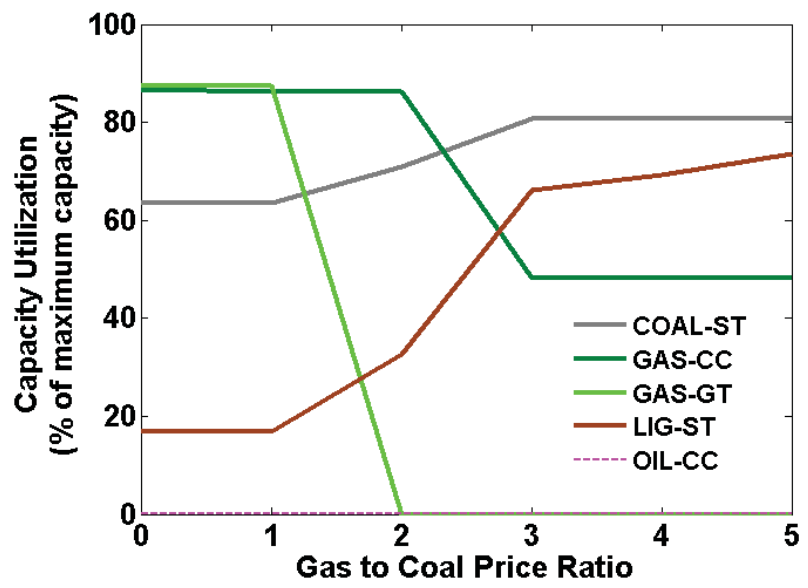

(b)

Fig.9: Capacity utilization of thermal power plants at a typical winter peak hour in scenario "Base" (a) $\mathrm{CO}_{2}$-price is $0 € /$ ton; (b) $\mathrm{CO}_{2}$-price is $40 € /$ ton

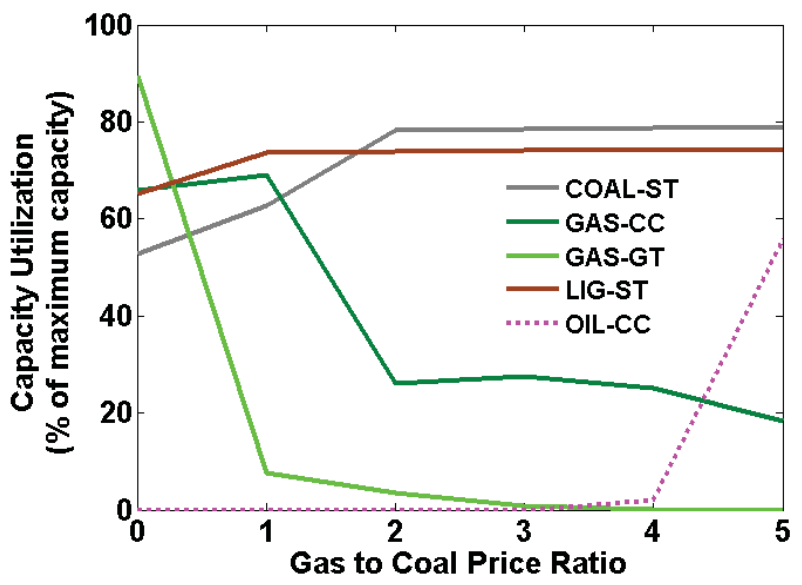

(a) 


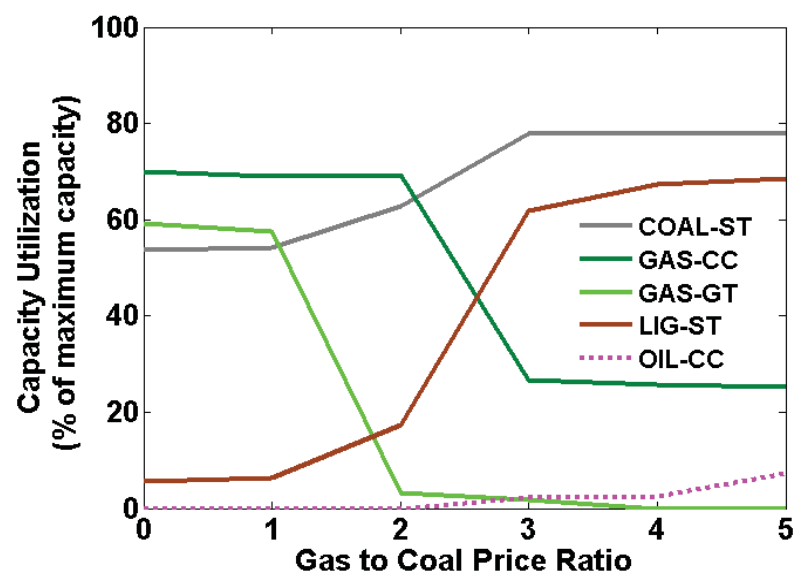

(b)

Fig.10: Capacity utilization of thermal power plants at a typical winter peak hour in scenario "WND-OPT" (a) $\mathrm{CO}_{2}$-price is $0 € /$ ton; (b) $\mathrm{CO}_{2}$-price is $40 € /$ ton

According to Fig. 9 or Fig. 10 , when increasing the $\mathrm{CO}_{2}$-price, the point, where the capacity utilization of gas combined-cycle plants starts to decrease, moves towards a higher gas price. At a positive $\mathrm{CO}_{2}$-price, the capacity utilization of gas turbine significantly reduces at a gas to coal price ratio of 2 . By comparing the capacity utilization of gas turbine between Fig. 10.a and Fig. 10.b, a significant reduction is noticed at a gas price of zero when increasing the $\mathrm{CO}_{2-}$ price. However, according to Fig. 9, this effect is negligible in baseline scenario. Additional reduction of the power produced by fossil-fired plants in scenario "WND-OPT" is balanced through a higher usage of energy storage to reduce the discarded wind energy.

According to Fig. 11.b, at a zero gas price, the storage output significantly increases in response to an additional increase in the $\mathrm{CO}_{2}$-price. This occurs because the system has the potential to reduce the discarded wind energy through an increased application of energy storage. As a result, discarded wind energy reduces at maximum by $5 \%(240 \mathrm{TWh})$ when the $\mathrm{CO}_{2}$-price is increased from 0 to $60 € /$ ton. This effect additionally contributes in the reduction of $\mathrm{CO}_{2}$ emissions, achieved through fuel switching. Thus, total abatement, achieved at 
a zero gas price, is higher in the "WND-OPT" scenario as compared to the base case (see Fig. 7.b and Fig. 8.b).

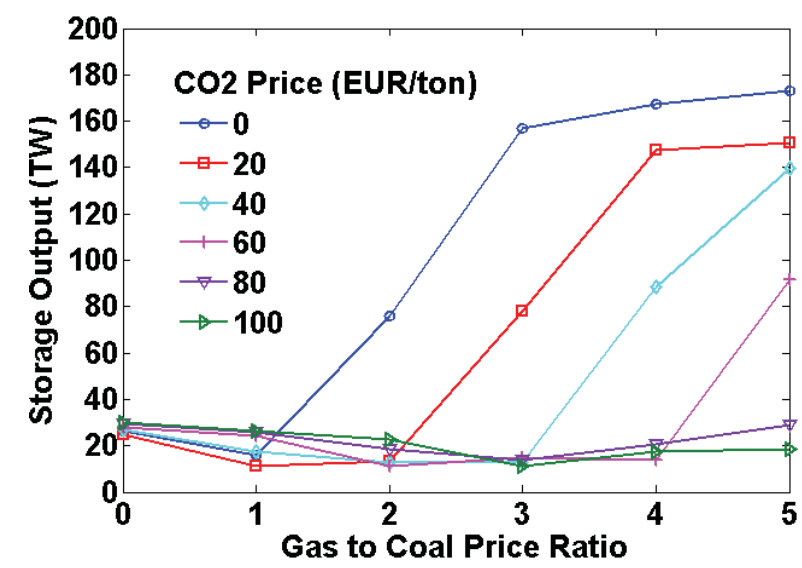

(a)

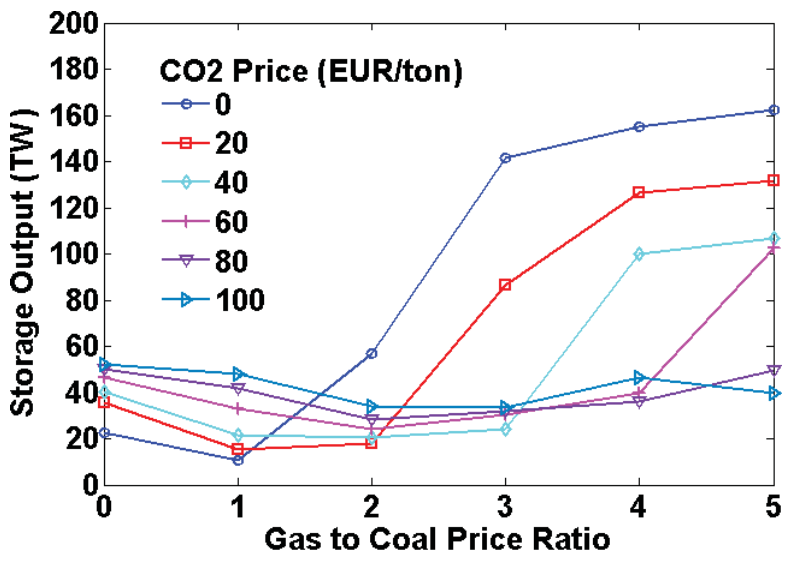

(b)

Fig.11: Storage output power at a typical winter peak hour (a) Scenario "Base"; (b) Scenario "WND-OPT"

According to Fig. 11, in both scenarios, when increasing the gas price, the storage output reduces until it reaches a minimum, where gas and coal are economically balanced at the given $\mathrm{CO}_{2}$-price. It starts to rise when the gas price is adequately high to make the application of coal-fired plants as base load generators economically attractive at the given $\mathrm{CO}_{2}$-price. As the gas price is further increased, application of energy storage becomes more and more economic to store the power produced by coal-fired plants for peak shaving purposes. It follows a similar trend in both scenarios. Therefore, the difference 
between the achieved abatement in scenario "WND-OPT" and the "Base" scenario is the highest at a gas price of zero and decreases afterwards (see Fig. 7.b and Fig. 8.b).

For instance, Fig. 12 shows a combined effect of load and fuel price on the abatement. At higher ranges of load and extreme levels of the gas price, $\mathrm{CO}_{2}$ emissions are not influenced by the $\mathrm{CO}_{2}$-price. The maximum abatement occurs at lower levels of electricity load and at a gas to coal price ratio of 2 .

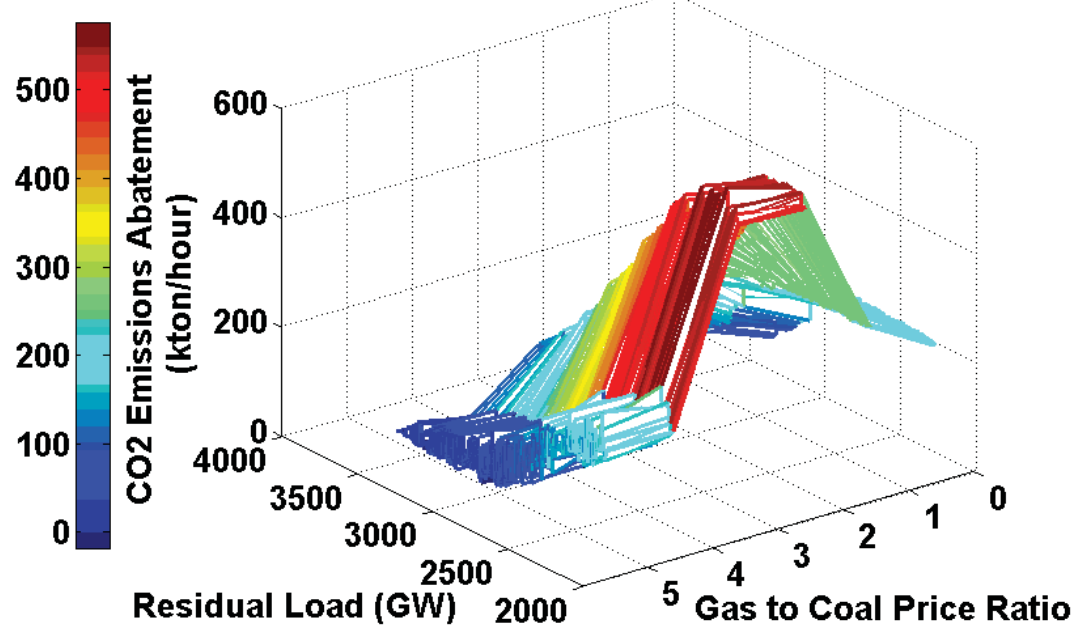

Fig.12: 3-dimensional representation of a combined influence of load and fuel price on $\mathrm{CO}_{2}$ emissions abatement in scenario "Base" at a $\mathrm{CO}_{2}$-price of $60 € /$ ton

Finally, a sensitivity study is performed on the influence of the oil price. The gas to coal price ratio is fixed at 3 (see Table D.1); the ratio of the oil price to the coal price is varied from zero to 5 . Fig. 13 shows the resulting $\mathrm{CO}_{2}$ emissions and the corresponding abatement at a typical winter peak hour over a range of oil to coal price ratios. At a zero $\mathrm{CO}_{2}$-price, when the oil price is reduced to zero, total $\mathrm{CO}_{2}$ emissions at this hour reach to around 2300 ktons (see Fig. 13.a). While the oil price is lower than the coal price including the additional emissions costs, oil-fired plants substitute the coal-fired plants, and total $\mathrm{CO}_{2}$ 
emissions reduces. When the oil to coal price ratio exceeds a certain limit, which varies by the $\mathrm{CO}_{2}$-price, power production from coal and the resulting emissions rise.

While increasing the oil price, the capacity utilization of coal-fired plants increases at the expense of oil. This creates opportunities for fuel switching, which can be utilized with increasing the $\mathrm{CO}_{2}$-price. Hence, the abatement rises when increasing the oil price. However, at any given $\mathrm{CO}_{2}$-price, there is a price ratio, which is adequately high to make further switching in favor of lower emitting source economically unattractive. Therefore, all the abatement lines reach a peak and fall afterwards. The peak of abatement mainly occurs at a fuel price ratio of 1 .

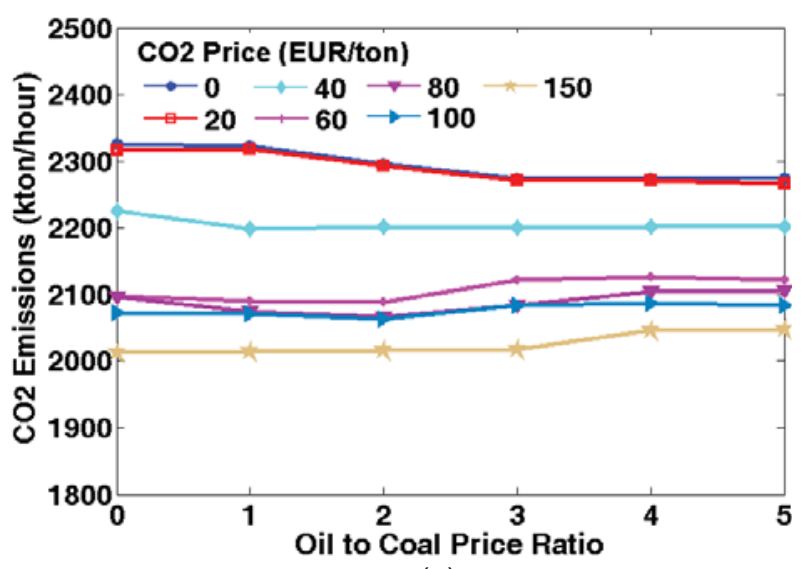

(a)

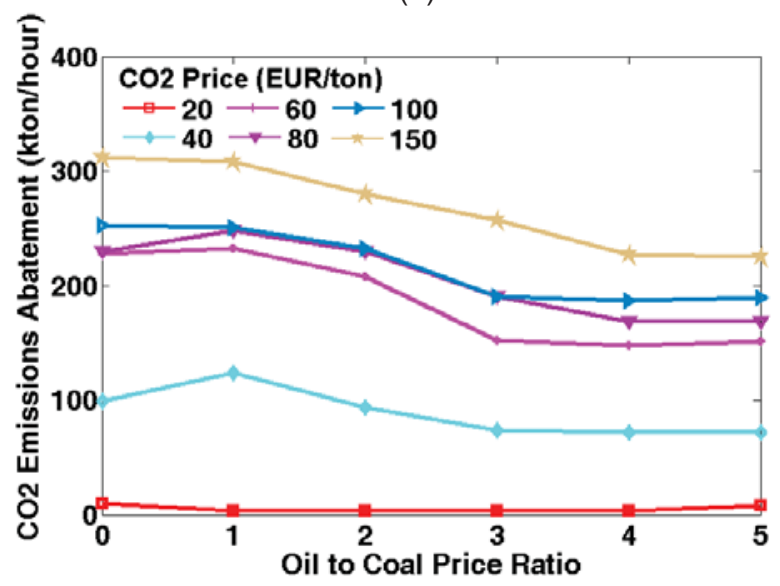

(b)

Fig.13 Influence of $\mathrm{CO}_{2}$-price and fuel price on $\mathrm{CO}_{2}$ emissions at a typical winter peak hour in scenario "Base" (a) $\mathrm{CO}_{2}$ emissions summed over all regions; (b) Corresponding abatement 


\subsubsection{Cumulative $\mathrm{CO}_{2}$ emissions}

In a short-term perspective, when the available capacity of power plants remains unchanged, a higher $\mathrm{CO}_{2}$-price changes the merit-order of power plants and leads to the reduction of emissions. The minimum specific abatement cost, which leads to switching between two technologies, is defined in (17); $U_{E m}$ is the minimum specific abatement costs in [€/ton]; $k_{\text {Opr }}$ represents the specific variable operation costs including fuel costs in [€/MWh $\mathrm{he}_{\mathrm{el}}$; $e$ is the emission factor in [ton/MWhe].

$$
v_{E m}=\frac{k_{O p r, 1}-k_{O p r, 2}}{e_{2}-e_{1}}
$$

Using the parameters, given in Table D.1 and Table D.2, the minimum specific abatement costs are calculated and are given in Table 1.

Table1: Minimum specific abatement costs

\begin{tabular}{|l|c|}
\hline \hline Technology & $\begin{array}{c}\text { Minimum specific abatement costs } \\
(€ / \text { ton })\end{array}$ \\
\hline LIG-ST - COAL-ST & 26 \\
\hline LIG-ST - GAS-CC & 38 \\
\hline COAL-ST - GAS-CC & 46 \\
\hline LIG-ST - GAS-GT & 88 \\
\hline COAL-ST - GAS-GT & 151 \\
\hline \hline
\end{tabular}

Thus, fuel switching occurs step-wise: when the $\mathrm{CO}_{2}$-price reaches the minimum abatement costs, fuel substitution starts and lasts till the technical limits are reached. Fig. 14 clarifies fuel switching effects in response to a given $\mathrm{CO}_{2}$-price. For instance, at a $\mathrm{CO}_{2}$-price of $60 € /$ ton, coal-fired units are replaced with gas combined-cycle plants. 


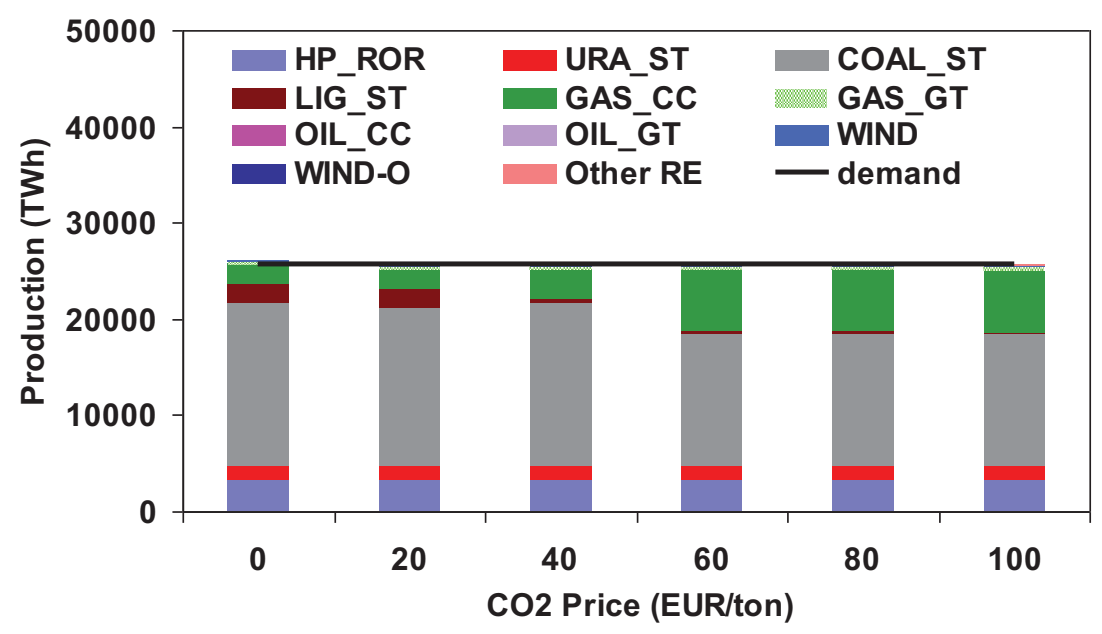

(a)

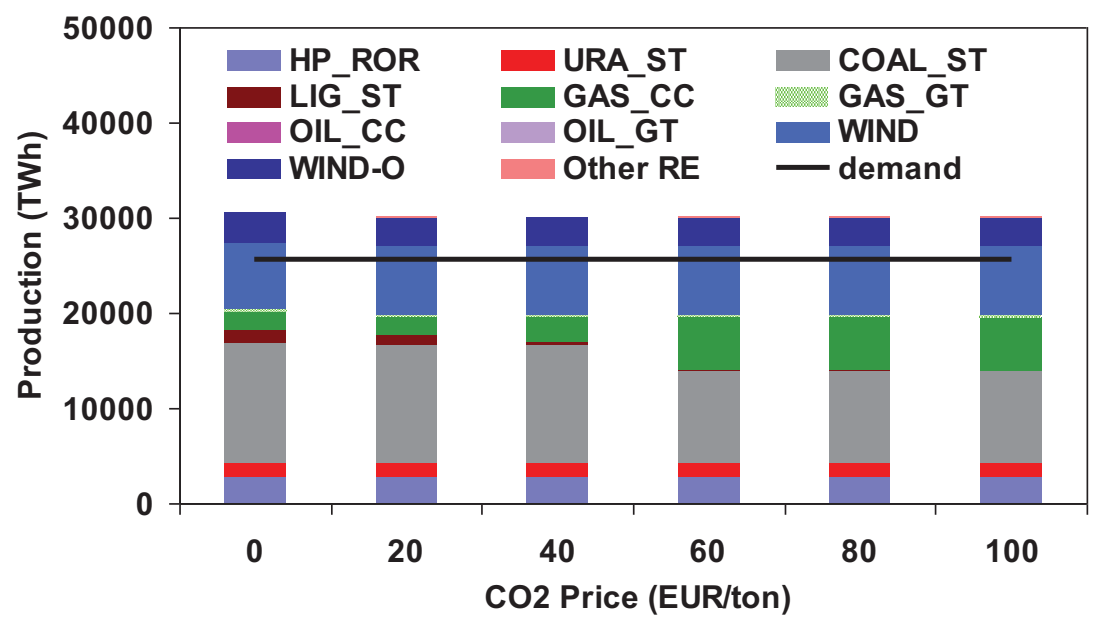

(b)

Fig.14: Total power production mix as a function of $\mathrm{CO}_{2}$-price (a) Scenario "Base"; (b) Scenario "WND-OPT" (constant fuel prices are used as it is given in Table D.1.)

Total annual $\mathrm{CO}_{2}$ emissions are visualized in Fig. 15 for different scenarios. It is concluded that no linear relationship exists between the $\mathrm{CO}_{2}$-price and the total abatement. This is significantly influenced by the structure of the power system and the available capacity of low emitting generation plants. 


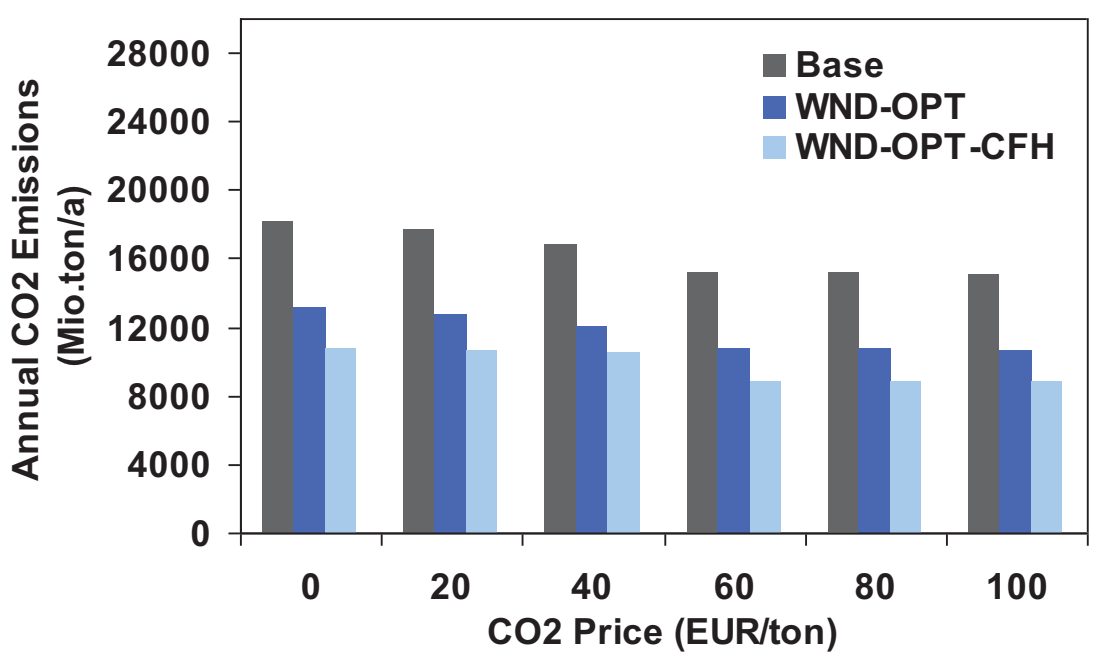

Fig.15: Total annual $\mathrm{CO}_{2}$ emissions as a function of $\mathrm{CO}_{2}$-price (constant fuel prices are used as it is given in Table D.1.)

\subsection{Long-term $\mathrm{CO}_{2}$ Emissions Abatement}

So far, it has been demonstrated that the $\mathrm{CO}_{2}$ emissions can be reduced by switching from high carbon fuels such as coal to low carbon fuels such as natural gas. However, for many world regions, this option has consequences on the security of supply, as they would then become dependent on the imported natural gas. Moreover, the potential is relatively limited. Ambitious emissions reduction targets can not be achieved without deployment of zero carbon energy sources such as wind and solar.

Thus, in this part, the focus is laid on the new investments in the world electricity sector, required to achieve long-term emissions reduction targets. Assuming that a global cap-and-trade system for emissions certificate trading is put into place, optimal configuration of a prospective global electricity system is investigated when global emissions caps are binding. Thus, in the following scenarios, production is constrained by regulated $\mathrm{CO}_{2}$ emissions. The $\mathrm{CO}_{2}$-limit is implemented as a global system constraint, i.e. through the optimization 
process it is assumed that reductions take place where it is cheapest to do so regardless of the geographical position.

\subsubsection{Influence of FRES on Marginal Price of $\mathrm{CO}_{2}$ Emissions}

At first, the effect of an ambitious global emissions reduction target of $38 \%$ below the level of emissions in year 2000 is studied. Different optimal structures of a global electricity system in year 2025 are taken into account; these differ in the share of produced electricity from FRES. In the baseline scenario, existing capacities of solar and wind power are set as upper capacity boundaries. In scenario "REOPT", penetration share of solar and wind energy is determined by the optimization model. In "RE50-" scenarios, solar and wind power production are constrained to satisfy $50 \%$ of the global electricity demand. The share of wind energy is increased from zero to $50 \%$ and $100 \%$ of the total solar and wind power production in scenarios "RE50-WP0", "RE50-WP50", and "RE50-WP100", respectively. Other assumptions are descried in section 4.2.1. Scenarios are summarized in Table 2.

Table 2: Scenarios and underlying assumptions

\begin{tabular}{|l|l|}
\hline \hline Scenario & Underlying assumptions \\
\hline Base & $\begin{array}{l}\text { - Total } \mathrm{CO}_{2} \text { emissions are limited to } 5745 \text { million tons. } \\
- \text { Extension of solar and wind power beyond today is not allowed. }\end{array}$ \\
\hline REOPT & $\begin{array}{l}\text { - Total } \mathrm{CO}_{2} \text { emissions are limited to } 5745 \text { million tons. } \\
- \text { Upper capacity boundary of solar and wind power at each region is the technical } \\
\text { petential. }\end{array}$ \\
\hline RE5WP0 & $\begin{array}{l}\text { - Total } \mathrm{CO}_{2} \text { emissions are limited to } 5745 \text { million tons. } \\
\text { potential. } \\
- \text { Solar and wind power are forced to satisfy } 50 \% \text { of global electricity demand. } \\
- \text { Wind share is } 0 \% \text { of total solar and wind power production. }\end{array}$ \\
\hline \hline
\end{tabular}




\begin{tabular}{|c|c|}
\hline RE50WP50 & $\begin{array}{l}\text { - Total } \mathrm{CO}_{2} \text { emissions are limited to } 5745 \text { million tons. } \\
\text { - Upper capacity boundary of solar and wind power at each region is the technical } \\
\text { potential. } \\
\text { - Solar and wind power are forced to satisfy } 50 \% \text { of global electricity demand. } \\
\text { - Wind share is } 50 \% \text { of total solar and wind power production. }\end{array}$ \\
\hline RE50WP100 & $\begin{array}{l}\text { - Total } \mathrm{CO}_{2} \text { emissions are limited to } 5745 \text { million tons. } \\
\text { - Upper capacity boundary of solar and wind power at each region is the technical } \\
\text { potential. } \\
\text { - Solar and wind power are forced to satisfy } 50 \% \text { of global electricity demand. } \\
\text { - Wind share is } 100 \% \text { of total solar and wind power production. }\end{array}$ \\
\hline
\end{tabular}

Total power production mix is shown in Fig. 16 . When implementing a $\mathrm{CO}_{2}$-limit while no possibility exists for extension of solar and wind power in baseline scenario, the production is characterized with an extensive application of gas combined-cycle and biomass power plants. As a result, the $\mathrm{CO}_{2}$-price is the highest.

Application of solar energy in scenario "RE50-WP0" allows increasing the utilization of coal-fired plants while the power production from gas is lower than the base case. Contribution of biomass is insignificant, and less power is produced from hydro and nuclear power plants in comparison with the base case. Increasing the share of wind energy in scenarios "RE50-WP50" and "RE50-WP100" allows even a higher application of coal-fired plants while the power production from gas is further reduced as compared to "RE50-WP0". However, the operation time of hydro and nuclear power plants is higher as compared to the solar-only case.

The explanation arises from the fact that the daily pattern of solar energy positively correlates with the diurnal behavior of electricity load. Thus, in scenario "RE50-WP0", during hours with a high gain of irradiation, there is a full integration of solar energy at specific sites. This leads to the reduction of the 
operation time of hydro and nuclear power plants as compared to other scenarios. However, in winter period and during hours with no gain of irradiation, the electricity demand is mainly satisfied with gas-fired units as well as hydro and nuclear power plants. Wind power production has a timely pattern, which is more evenly distributed between the hours of day and night and through different seasons. Thus, when increasing the share of wind energy, total power production from emission-free hydro and nuclear power plants is increased from its level in the solar-only case. This allows a higher utilization of coal-fired plants, and the power production from gas-fired plants can be reduced while the same level of abatement is achieved as in the solar-only case.

According to Fig. 16, marginal price of $\mathrm{CO}_{2}$ emissions decreases when increasing the share of wind energy; it reaches to its lowest level in scenario "REOPT". In this case, the share of wind energy reaches to $52 \%$ of the global electricity demand.

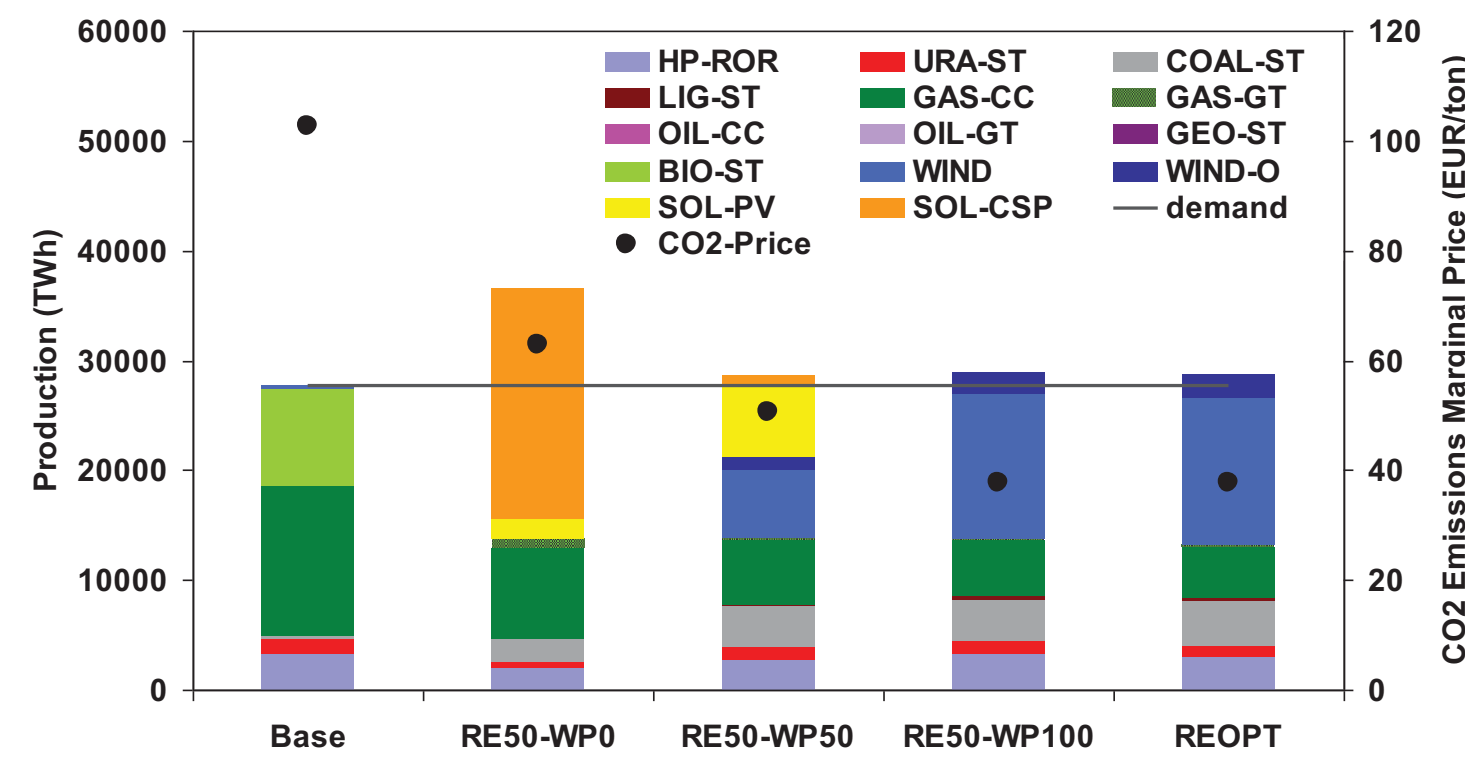

Fig.16: Total power production mix and marginal price of $\mathrm{CO}_{2}$ emissions 


\subsubsection{Influence of International Electricity Exchange in a Prospective Low- carbon Electricity Generation System}

Challenges arise when integrating a high share of solar and wind energy into an electricity system mainly due to their short-term fluctuations. Smoothening effects, captured in a dispersed generation structure, can alleviate the problem. Not only statistical smoothening effects of geographical aggregation but also inter-continental, seasonal anti-correlations may provide a competitive framework for the deployment of solar and wind energy. Therefore, the focus of this subsection is laid on the influence of international electricity exchange in an ideal, globally-interconnected electricity supply structure.

Here, a long-term horizon from 2020 to 2040 in 5 -year time steps is taken into account; the focus is laid on the role of a global grid as a solution option for large-scale integration of FRES. In scenario "GOPT", the new capacity of interregional power transmission interconnections is optimized. To evaluate the absolute impact of a global grid, the scenario "No-GE" is also considered, having no possibility for extension of the power transmission network while other underlying assumptions are similar to scenario "GOPT". As before, it is assumed that nuclear and hydro power plants are not expandable beyond the installed capacities. New installations of geothermal power plants are restricted according to the planned capacities, given in (UDI WEPP, 2010). The capacity of energy storage is fixed at the total capacity of year 2009. Techno-economic parameters of each power plant technology are assumed to be uniform through all regions. For the new vintages, the conversion efficiency increases while the investment costs reduce over the future time horizons. Techno-economic parameters of new power plants and projected fuel prices are given in 
Table D.3, Table D.4, and Table D.5. For inter-regional transmission of electricity, the costs of to the 500kV HVDC technology, given in (ABB, 2009), are used. Scenarios are described in Table 3.

The IPCC Working Group one proposed an early action scenario for 550 ppmv concentration level (IPCC, 2000; Manne and Richels, 1997). This is used here to limit the total $\mathrm{CO}_{2}$ emissions from the power sector in scenarios with the postfix of "-CO2H". In a more stringent scenario, represented with a postfix of "-CO2L", $\mathrm{CO}_{2}$ emissions limits are tightened according to the first category of stabilization scenarios in IPCC fourth Assessment Report (Nakicenovic, 2007; IPCC, 2007). The $\mathrm{CO}_{2}$ emissions path is set to the minimum path, proposed in (Nakicenovic, 2007), which leads to the stabilization of $\mathrm{CO}_{2}$ only concentrations at the level of 350 ppmv by 2100 . The contribution share of the power sector in total abatement is estimated from the historical data (Wheeler and Ummel, 2008; Manne and Richels, 1997). The implemented $\mathrm{CO}_{2}$ limits are represented in Table 4.

Table 3: Scenarios and underlying assumptions

\begin{tabular}{|l|l|}
\hline \hline Scenario & Underlying assumptions \\
\hline GOPT-CO2L & $\begin{array}{l}-\mathrm{CO}_{2} \text {-limit is based on } 350 \text { ppmv concentration level. } \\
- \text { Inter-regional power transmission capacities are optimized. }\end{array}$ \\
\hline GOPT-CO2H & $-\mathrm{CO}_{2}$-limit is based on 550 ppmv concentration level. \\
& - Inter-regional power transmission capacities are optimized. \\
\hline NoGE-CO2L & $-\mathrm{CO}_{2}$-limit is based on 350 ppmv concentration level. \\
& - Inter-regional power transmission capacities are fixed as today. \\
\hline NoGE-CO2H & $-\mathrm{CO}_{2}$-limit is based on 550 ppmv concentration level. \\
& - Inter-regional power transmission capacities are fixed as today. \\
\hline \hline
\end{tabular}




\begin{tabular}{|l|l|}
\hline \hline GOPT-CO2L-NoBio & $\begin{array}{l}-\mathrm{CO}_{2} \text {-limit is based on } 350 \text { ppmv concentration level. } \\
\text { - Inter-regional power transmission capacities are optimized. } \\
- \text { Extension of biomass beyond today is not allowed. }\end{array}$ \\
\hline NoGE-CO2L-NoBio & $\begin{array}{l}-\mathrm{CO}_{2} \text {-limit is based on } 350 \text { ppmv concentration level. } \\
- \text { Inter-regional power transmission capacities are fixed as today. } \\
\text { - Extension of biomass beyond today is not allowed. }\end{array}$ \\
\hline GOPT-CO2L-NoBio-SOL & $\begin{array}{l}\text { - CO} 2 \text {-limit is based on } 350 \text { ppmv concentration level. } \\
- \text { Inter-regional power transmission capacities are optimized. } \\
- \text { Extension of biomass beyond today is not allowed. } \\
- \text { Costs of solar power plants are reduced by } 50 \% .\end{array}$ \\
\hline NoGE-CO2L-NoBio-SOL & $\begin{array}{l}- \text { CO } 2 \text {-limit is based on } 350 \text { ppmv concentration level. } \\
- \text { Inter-regional power transmission capacities are fixed as today. } \\
- \text { Extension of biomass beyond today is not allowed. } \\
- \text { Costs of solar power plants are reduced by } 50 \% .\end{array}$ \\
\hline \hline
\end{tabular}

Table 4: Implemented $\mathrm{CO}_{2}$ Limits in million metric tons

\begin{tabular}{|l|c|c|c|c|c|}
\hline \hline Scenario & Year 2020 & Year 2025 & Year 2030 & Year 2035 & Year 2040 \\
\hline $\mathrm{CO} 2 \mathrm{H}$ & 10059 & 10335 & 10611 & 10777 & 10943 \\
\hline $\mathrm{CO} 2 \mathrm{~L}$ & 6107 & 4698 & 3758 & 2819 & 2067 \\
\hline \hline
\end{tabular}

The optimal power generation capacity mix, summed over all regions, obtained from the first four scenarios is illustrated in Fig. 17. In scenario "GOPT-CO2H", the total wind power capacity is 2637 GW in 2020 and rises to 9933 GW by 2040. The average wind power capacity factor is $27 \%$, and its penetration share reaches to $55 \%$ of the global electricity demand by 2040 . In the more stringent scenario, named "GOPT-CO2L", the installed capacity for wind power production rises from 4913 to 15729 GW through the time horizon. Implementing a tighter $\mathrm{CO}_{2}$-limit, the coal-fired capacity is reduced while the capacity of gas-fired plants is higher as compared to the "GOPT-CO2H" 
scenario. With the assumed costs and conversion efficiency, solar power plants are not selected for large-scale penetration.

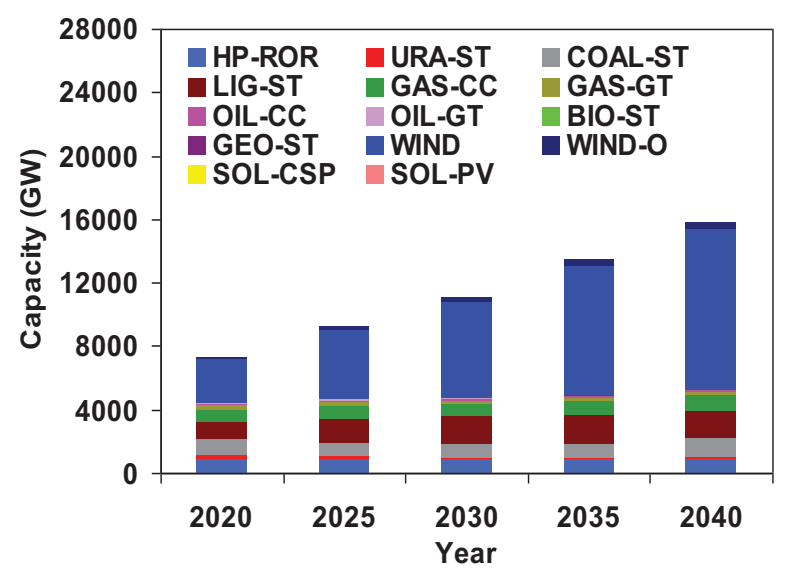

(a)

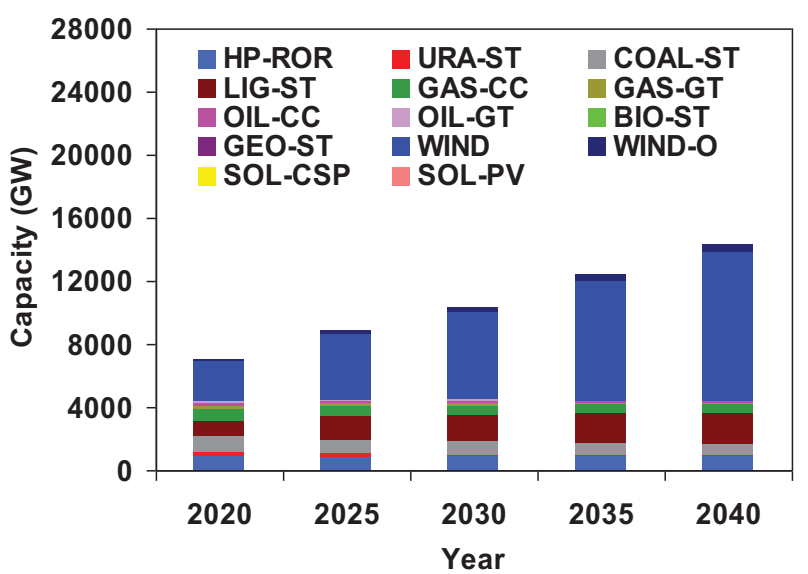

(b)

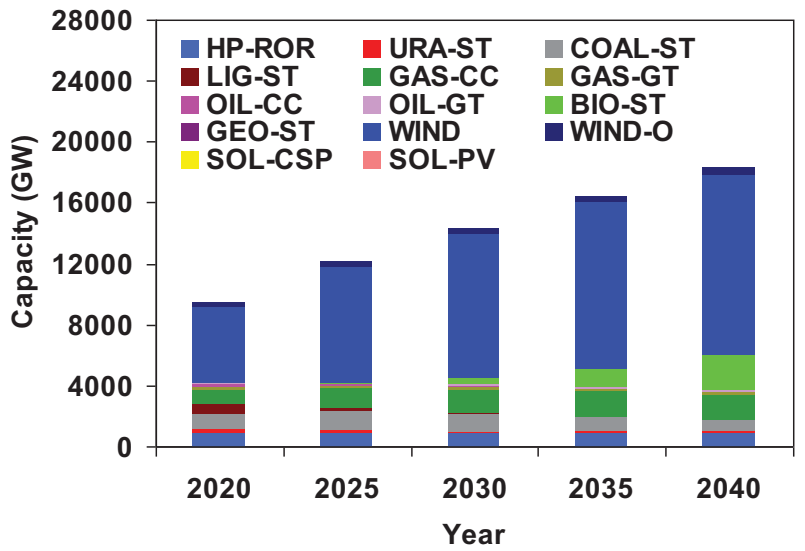

(c) 


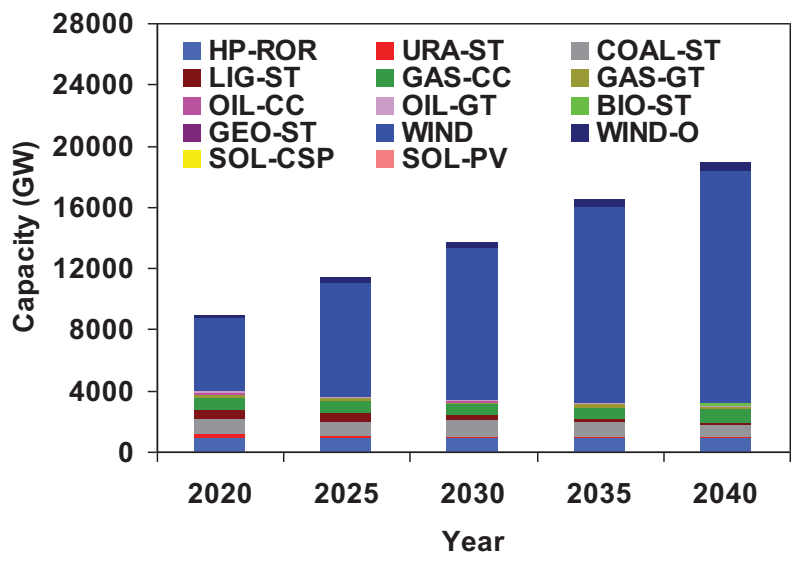

(d)

Fig.17: Global power generation capacity mix over the time horizon 2020-2040 (a) Scenario "NoGECO2H"; (b) Scenario "GOPT-CO2H"; (c) Scenario "NoGE-CO2L"; (d) Scenario "GOPT-CO2L"

Furthermore, it is concluded that if the extension of biomass is restricted in scenario "NoGE-CO2L-NoBio", total installed capacity for solar electricity generation significantly increases in the final period; it rises from 3 GW in 2035 to 379 GW by 2040 (see Fig. 18).

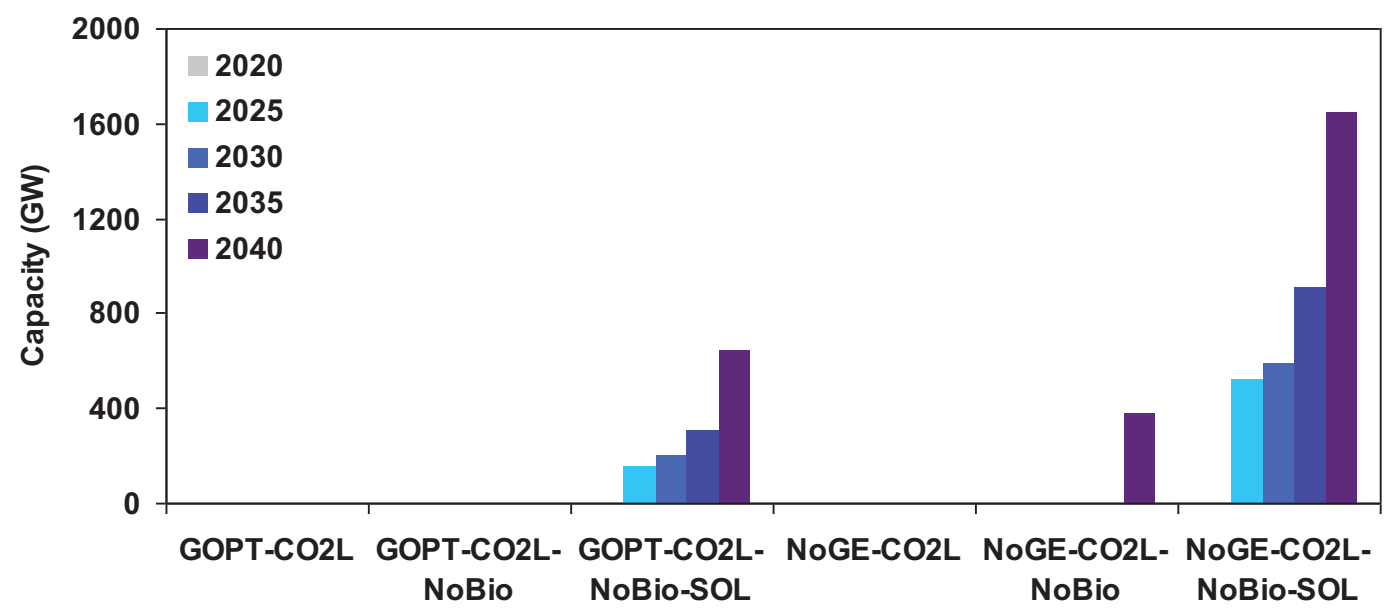

Fig.18: Total capacity of SOL-PV and SOL-CSP over the time horizon 2020-2040

An ideal globally-interconnected structure allows making an optimal usage of spatial de-correlations of wind power production and increases the capacity credit of wind power. An optimal structure of the global power transmission grid is shown in Fig. 19. Inter-regional power transmission lines with a maximum capacity of $157 \mathrm{GW}$ and $392 \mathrm{GW}$ are installed in scenarios "GOPT-CO2H" and 
"GOPT-CO2L", respectively to transmit wind electricity from regions, having a highly concentrated potential, to the distant consuming regions.

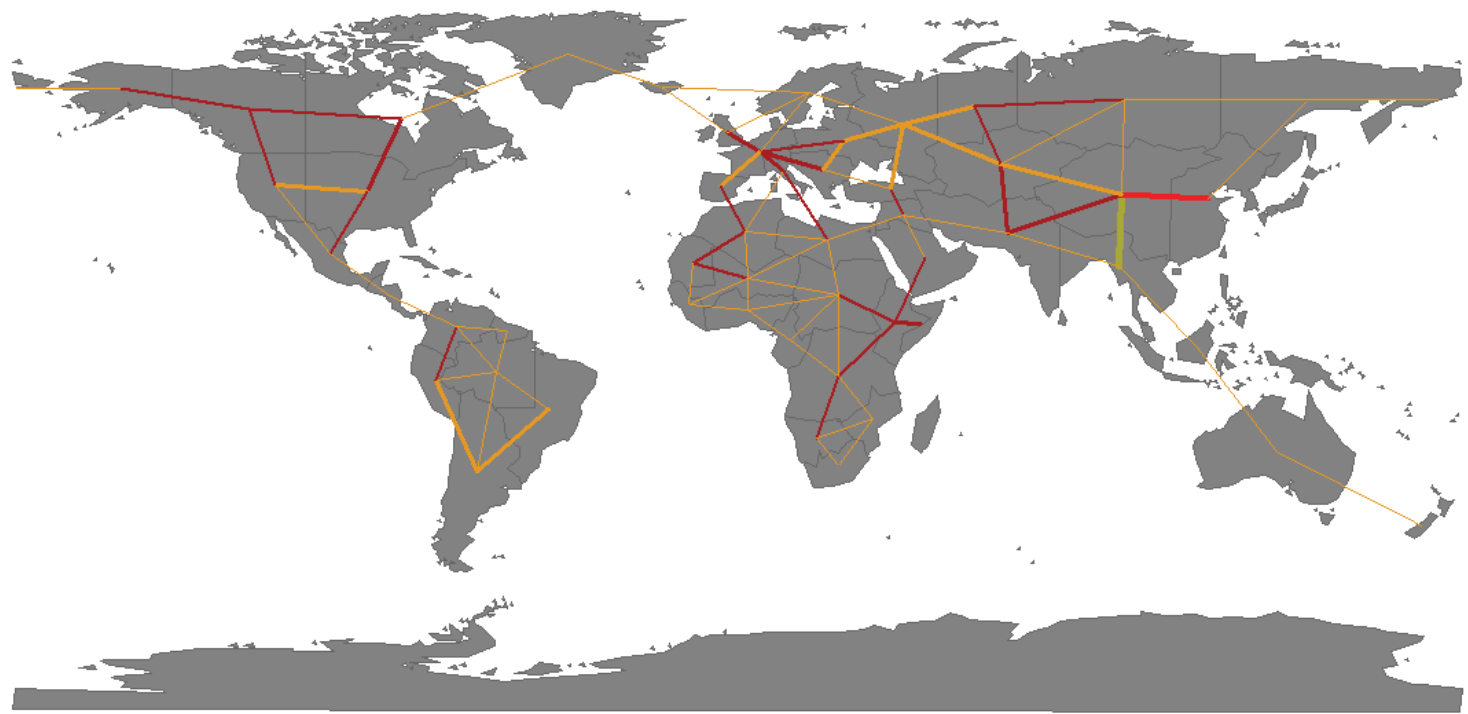

\section{Capacity (GW)}

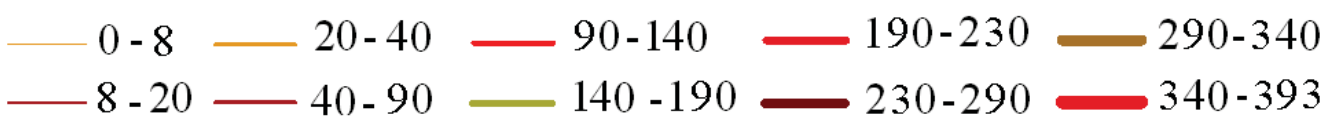

(a)

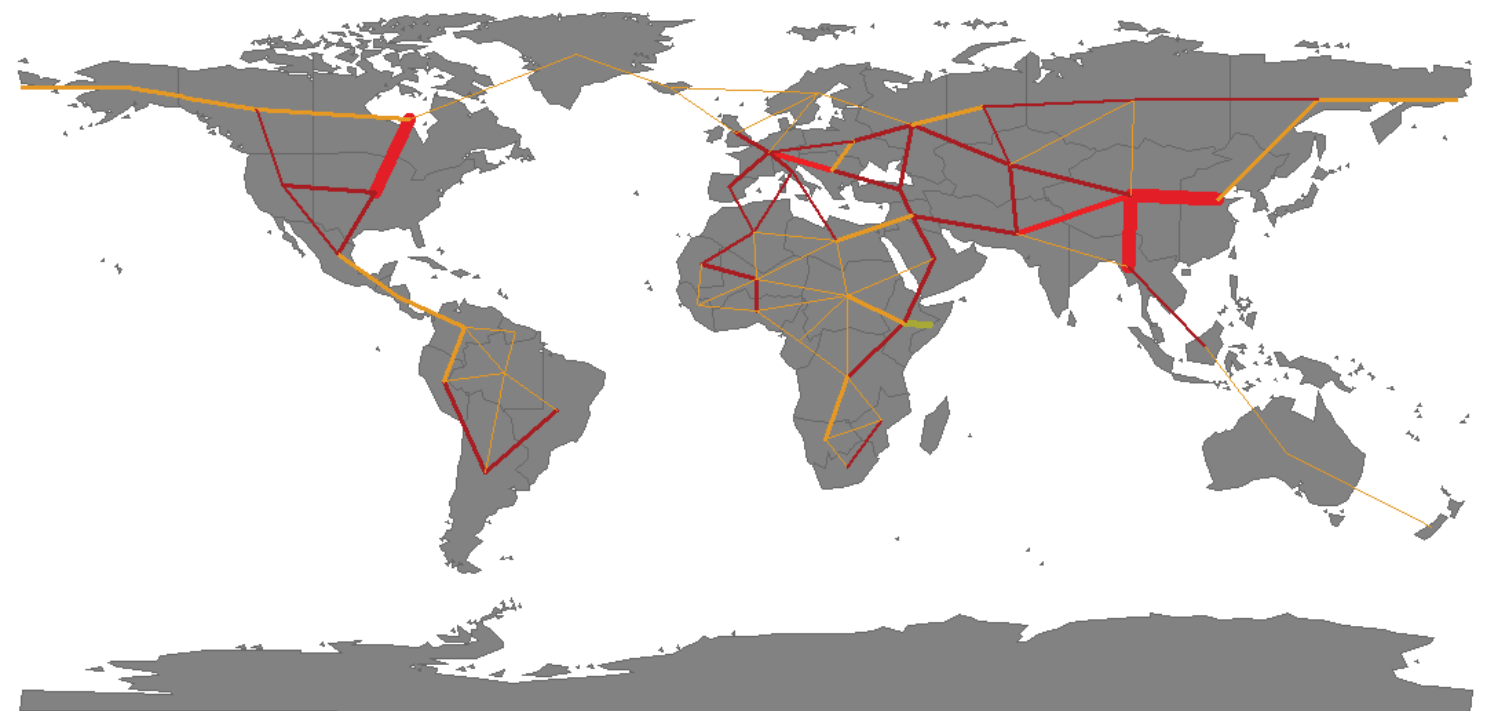

\section{Capacity (GW)}

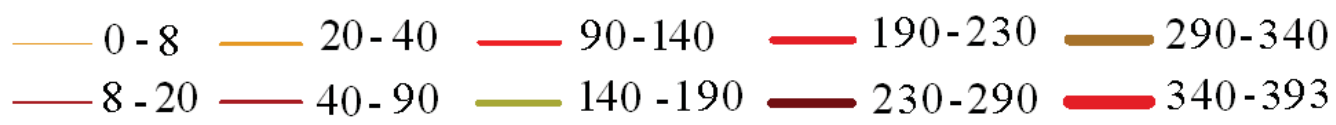

(b)

Fig.19: Optimal power transmission grid structure in year 2040 (a) Scenario "GOPT-CO2H"; (b) Scenario "GOPT-CO2L" 
The influence of a global grid can be realized by comparing "NoGE-" scenarios with "GOPT-" scenarios. Fig. 17 clarifies the overinstallation of power generation capacities, occurring in scenarios "NoGE-CO2L" and "NoGE-CO2H"; higher capacities for gas-fired generation, biomass and wind power production are required to achieve the same level of abatement as it is achieved in scenarios "GOPT-CO2L" and "GOPT-CO2H", respectively.

In scenario "GOPT-CO2H", the $\mathrm{CO}_{2}$-price does not significantly increase through the considered time horizon and remains near $17 € /$ ton (see Fig. 20). However, in scenario "NoGE-CO2H", it rises to $33 € /$ ton by 2040 . This effect becomes even more evident when tightening the $\mathrm{CO}_{2}$-limit while the utilization of biomass is restricted. For instance, in scenario "NoGE-CO2L-NoBio-SOL", the $\mathrm{CO}_{2}$-price significantly rises to $167 € /$ ton by 2040 .

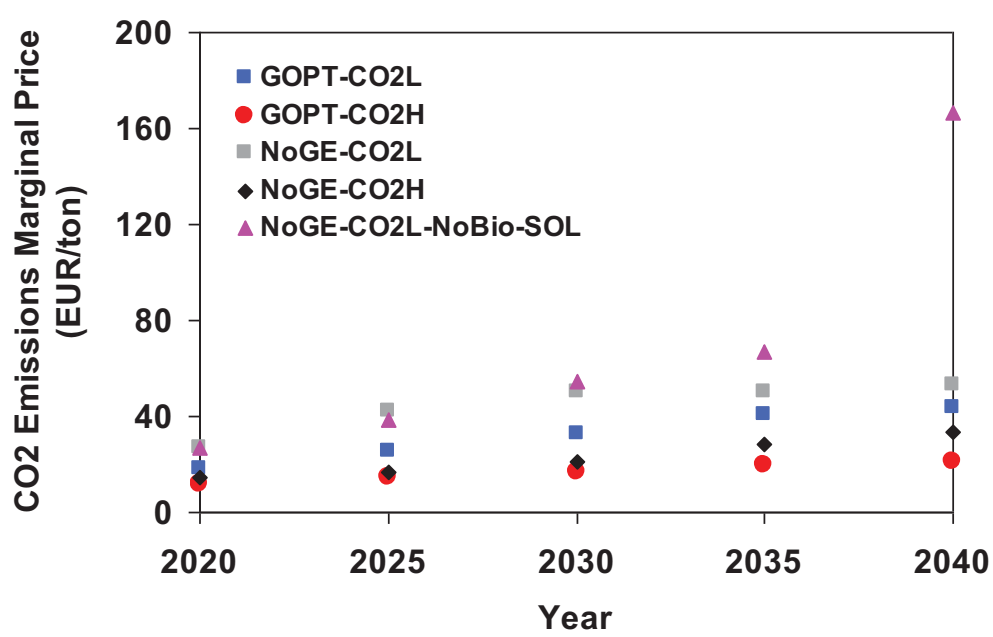

Fig.20: Development of $\mathrm{CO}_{2}$-certificate price over the time horizon 2020-2040

\section{Conclusions and Outlook}

In this paper, a multi-regional electricity system investment planning model has been applied to study complex interactions of different factors, influencing $\mathrm{CO}_{2}$ emissions of the global electricity generation system. 
At first, the global model was examined versus a real power production mix to validate its appropriateness for modeling electricity generation systems. Mainly by adjusting the availabilities of coal- and lignite- fired plants, simulation results correspond to the actual generation. The calibrated model was then applied to quantify the potential for reducing emissions in response to a global carbon price with an existing fleet of generation plants, i.e. by means of fuel switching. It has been concluded that the total emissions would be reduced by $5 \%$ (several hundreds of million tons) if a $\mathrm{CO}_{2}$-price of $18 € /$ ton existed in all countries through the year 2006 .

Through sensitivity study, it was shown that the achievable abatement in response to a $\mathrm{CO}_{2}$-price is significantly influenced by the structure of the electricity system as well as load and fuel price relationships. It is concluded that a complex relationship exists between the abatement and the influencing factors such as $\mathrm{CO}_{2}$-price, fuel prices, and electricity load. Indeed, all these factors must lie within a specific range at the same time that fuel switching can occur.

When a time horizon from 2020 to 2040 is taken into account, optimization results show that wind energy is extensively employed to meet ambitious emissions reduction targets. It was demonstrated that an ideal global grid has a great influence to mitigate negative consequences caused by the integration of FRES due to their short-term variability and seasonal dependencies.

It is worth mentioning that in the applied optimization model, technical restrictions of power plants are respected at a technology level rather than on a power plant basis as in a unit commitment problem. Thus, required investments in flexible generation plants and the marginal price of $\mathrm{CO}_{2}$ emissions are 
underpredicted while the share of FRES that can feasibly be integrated into the power system is overestimated. However, regarding the scale of the problem, addressed here, these influences are very low in proportional terms.

Furthermore, the main considered policy instrument in this analysis is the implemented certificate price or the $\mathrm{CO}_{2}$ emissions limit. The subsidies aspects in the energy sector are not explicitly included in this paper. However, the influence of financial incentives for further application of renewable energies in different world regions as well as the influence of financial constraints in developing countries must be investigated in detail.

Finally, the focus of this paper has been laid on the influences of power system integration of FRES while international electricity exchange is taken into account as a main solution option to relieve the problem of intermittency of the primary energy source. However, the influence of different energy storage technologies to provide the required balancing needs for large-scale integration of solar energy must be studied in further investigations.

\section{References}

ABB Power Technologies AB Grid Systems -HVDC (2009), Ultra high voltage DC systems, http://www.abb.com/hvdc.

Aboumahboub, T., Schaber, K., Tzscheutschler, P., Hamacher, Th. (2010). Optimal configuration of a renewable-based electricity supply sector, in: WSEAS Transactions on Power Systems 5, 120-129.

Bishop, J.K.B., Potylitsina, T., Rossow, W.B. (2000). Documentation and description of surface solar irradiance data sets produced for SeaWiFS, NASA Grant, Department of Applied Physics, Columbia University, USA.

Brückl, O. (2005). Global technical potential of electricity production from wind energy, Internal final report for BMW AG Study, Institute for Energy Economy and Application Technology (IfE), Technische Universität München, Germany.

Dantzig, G.B., Thapa, M.N. (1997). Linear programming 1 \& 2, Springer Series in Operations Research and Financial Engineering, New York. 
Delarue, E. (2009). Modeling electricity generation systems - Development and application of electricity generation optimization and simulation models with particular focus on $\mathrm{CO}_{2}$ emissions, PhD thesis, Division of Applied Mechanics and Energy Conversion, Katholieke Universiteit Leuven, Belgium.

Energy Information Administration (EIA) (2010). International electricity data, http://www.eia.gov/electricity/data.

ENTSO-E European Network of Transmission System Operators for Electricity (2009). Statistical database, http://www.entsoe.eu/resources/data-portal.

Estonian Power Transmission System Operator Elerging OÜ (2009). http://www.elering.ee, "Personal Communication".

European Environmental Agency (EEA) (2009). Europe's onshore and offshore wind energy potential - an assessment of environmental and economical constraints, EEA technical report.

Global Wind Energy Council (GWEC) and Greenpeace International (2006). Global Wind Energy Outlook.

Han, W.E., Ward, D.J. (2007). Internal final report on EFDA TIMES model - electricity sector update task. EURATOM/UKAEA Fusion Association, Culham Science Centre, Abingdon, UK.

Heitmann, N., Hamacher, Th. (2009). Stochastic model of the German electricity system, in: Optimization in the Energy Industry, Energy Systems 3, 365-385.

Hoogwijk, M.M. (2004). On the global and regional potential of renewable energy sources, PhD Thesis, Universiteit Utrecht, Netherlands.

Institute for Energy Economy and Application Technology (IfE) (2010). Power plants database, Technische Unversität München, Germany.

International Energy Agency (IEA) and Nuclear Energy Agency (NEA). (2005). Projected costs of generating electricity.

International Energy Agency (IEA) and Nuclear Energy Agency (NEA). (2010). Projected costs of generating electricity.

International Institute for Applied Systems Analysis (IIASA) (2009). Greenhouse Gas Initiative (GGI) Database, http://www.iiasa.ac.at/web-apps/ggi.

International Energy Agency (IEA) (2002). World Energy Outlook.

International Energy Agency (IEA) (2006). World Energy Outlook.

International Energy Agency (IEA) (2007). World Energy Outlook.

Intergovernmental Panel on Climate Change (IPCC) (2000). Special report on emission scenarios - a special report of working group III.

Intergovernmental Panel on Climate Change (IPCC) (2007). Fourth Assessment Report (AR4).

Manne, A., Richels, R. (1997). On stabilizing $\mathrm{CO}_{2}$ concentrations - Cost-effective emission reduction strategies, International Journal of Environmental Modeling and Assessment, Vol. 2, 251-265.

Mathur, J., Bansal, N.K., Wagner, H.J. (2003). Investigation of greenhouse gas reduction potential and change in technological selection in Indian power sector, Energy Policy, 31, 12351244. 
Nakicenovic, N. (2007). World Energy Outlook 2007: $\mathrm{CO}_{2}$ emissions pathways compared to long-term $\mathrm{CO}_{2}$ stabilization scenarios in the literature and IPCC Assessment Report 4, IIASA and Technische Unversität Wien, Austria.

Newcomer, A., Blumsack, S.A., Apt, J., Lave, L.B., Morgan, M.G. (2008). Short run effects of a price on carbon dioxide emissions from U.S. electric generators, Environmental Science and Technology 42, No.9.

Norgaard, P., Holttinen, H. (2004). A multi-turbine power curve approach, Nordic Wind Power Conference, Chalmers University of Technogy, Sweden.

Rosenthal, R.E. (2008). GAMS A User's Guide, GAMS Development Corporation, Washington, DC, USA.

Roth, H., Kuhn, Ph. (2008). Technik und Kosten Szenarien der Strombereitstellung in Deutschland bis 2040, Internal technical report, Institute for Energy Economy and Application Technology (IfE), Technische Universität München, Germany.

Sander \& Partner GmbH (2009). World Wind Atlas, http://www.sanderpartner.ch.

Tzscheutschler, P. (2005). Global technical potential of solar thermal electricity, PhD Thesis, Institute for Energy Economy and Application Technology (IfE), Technische Universität München, Germany.

UDI World Electric Power Plants Data Base (WEPP). (2009). Data base description and research methodology, Platts, UDI Products Group, Washington, USA.

UK National Grid Company web site (2009). http://www.nationalgrid.com/uk/.

Vestas Wind Systems A/S. (2009). V90-3.0 MW an efficient way to more power, http://www.vestas.com.

VGB POWER TECH. (2008) Tätigkeitsbericht 2007/2008, Report by VGB POWER TECH, Essen, Germany.

Wheeler, D., K.Ummel. (2008) Calculating CARMA. global estimation of $\mathrm{CO}_{2}$ emissions from the power sector, Center for Global Development, http://www.carma.org.

World Alliance for Decentralized Energy (WADE). (2005). Projected costs of generating electricity (2005 Update), WADE's Response to the Report of the International Energy Agency and the Nuclear Energy Agency.

van Vuuren, D.P., Hof, A.F., den Elzen, M.G.J. (2009). Meeting the $2^{\circ} \mathrm{C}$ target - from climate objective to emission reduction measures, Netherlands Environmental Assessment Agency (PBL), Bilthoven, Netherlands.

Zickermann, Y. (2005): Approximation of typical load curves for different continents and climate zones, Internal final report, Institute for Energy Economy and Application Technology (IfE), Technische Universität München, Germany. 


\section{Appendix}

\section{A. Model Geographical Structure}

The global, multi-regional electricity system optimization model, developed and applied in this study, comprises 50 regions. Model regions are described in Table A.1.

Table A.1: Description of model regions

\begin{tabular}{|c|c|c|}
\hline Model region & Region name & Comprising countries (ISO 2-digit) \\
\hline R1 & SAM-S & AR, CL, UY, BO, PY \\
\hline R2 & BR-E & BR-East \& South \\
\hline R3 & BR-W & BR-North \& West \\
\hline R4 & SAM-N1 & PE, EC \\
\hline R5 & SAM-N2 & $\mathrm{CO}, \mathrm{VE}, \mathrm{AG}, \mathrm{AN}, \mathrm{AW}, \mathrm{BB}, \mathrm{DM}, \mathrm{DG}, \mathrm{GP}, \mathrm{KN}, \mathrm{LC}, \mathrm{MQ}, \mathrm{MS}, \mathrm{TT}, \mathrm{VC}, \mathrm{GD}, \mathrm{VG}$ \\
\hline R6 & SAM-N3 & GF, GY, SR \\
\hline R7 & CAM & GT, BZ, SV, HN, NI, CR, PA, BS, CU, DO, HT, JM, PR, VI, KY, TC \\
\hline R8 & MEX & $\mathrm{MX}$ \\
\hline R9 & USA-W & US-West \\
\hline R10 & USA-E & US-East \\
\hline R11 & AK & Alaska \\
\hline R12 & CAN-W & CA-West \\
\hline R13 & CAN-E & CA-East \\
\hline R14 & GL & GL \\
\hline R15 & NAF-NE & EG, LY \\
\hline R16 & NAF-NW & $\mathrm{DZ}, \mathrm{MA}, \mathrm{TN}$ \\
\hline R17 & AF-NM & $\mathrm{SD}, \mathrm{TD}, \mathrm{CF}$ \\
\hline R18 & AF-W1 & ML, NE \\
\hline R19 & AF-W2 & $\mathrm{EH}, \mathrm{CV}, \mathrm{MR}$ \\
\hline R20 & AF-W3 & $\mathrm{BJ}, \mathrm{BF}, \mathrm{Cl}, \mathrm{GH}, \mathrm{NG}, \mathrm{TG}$ \\
\hline R21 & AF-W4 & LR, SL, GN, GW, SN, GM \\
\hline
\end{tabular}




\begin{tabular}{|c|c|c|}
\hline R22 & AF-M & $\mathrm{CM}, \mathrm{GQ}, \mathrm{GA}, \mathrm{CG}, \mathrm{ST}$ \\
\hline R23 & AF-S1 & $\mathrm{CD}, \mathrm{TZ}, \mathrm{UG}, \mathrm{RW}, \mathrm{BI}, \mathrm{ZM}, \mathrm{AO}$ \\
\hline R24 & AF-E1 & ER, ET, DJ, KE \\
\hline R25 & AF-E2 & So \\
\hline R26 & AF-S2 & MW, MZ, ZW, KM, YT, MG \\
\hline R27 & AF-S3 & NA, BW \\
\hline R28 & ZA & ZA,LS, SZ \\
\hline R29 & AS-W1 & AM, GE, AZ, TR \\
\hline R30 & AS-W2 & SY, IQ, IL, LB, JO, KW, CY, PS \\
\hline R31 & AS-W3 & $\mathrm{SA}, \mathrm{AE}, \mathrm{YE}, \mathrm{OM}, \mathrm{QA}, \mathrm{BH}$ \\
\hline R32 & CAS & $\mathrm{KG}, \mathrm{KZ}, \mathrm{TJ}, \mathrm{TM}, \mathrm{UZ}$ \\
\hline R33 & AS-S & IN, LK, MV, AF, PK, IR \\
\hline R34 & AS-E1 & MN, CN-West \\
\hline R35 & AS-E2 & CN-East, JP,KP, KR, HK, TW \\
\hline R36 & AS-SE1 & $\mathrm{MM}, \mathrm{KH}, \mathrm{LA}, \mathrm{TH}, \mathrm{VN}, \mathrm{BO}, \mathrm{BT}, \mathrm{NP}$ \\
\hline R37 & AS-SE2 & $\mathrm{BN}, \mathrm{TL}, \mathrm{ID}, \mathrm{MY}, \mathrm{PH}, \mathrm{SG}, \mathrm{PG}$ \\
\hline R38 & RU-W & Russia-West \\
\hline R39 & RU-M & Russia-Central \\
\hline R40 & RU-E & Russia-East \\
\hline R41 & RU-FE & Russia-Far East \\
\hline R42 & AUS & Australia \\
\hline R43 & $\mathrm{NZ}$ & New Zealand \\
\hline R44 & EU-1 & EE, LV, LT, BY, UA, MD, PL,CZ \\
\hline R45 & EU-2 & SK, AT, HU, SI, HR, RS, BG, BA, ME, MK, AL, GR, RO \\
\hline R46 & EU-3 & DE, NL, BE, LU, FR, DK \\
\hline R47 & EU-4 & $\mathrm{CH}, \mathrm{LI}, \mathrm{MC}, \mathrm{SM}, \mathrm{IT}, \mathrm{MT}$ \\
\hline R48 & EU-5 & $A D, E S, P T, G I$ \\
\hline R49 & EU-6 & $\mathrm{NO}, \mathrm{SE}, \mathrm{FI}$ \\
\hline R50 & EU-7 & IE, GB, IS \\
\hline
\end{tabular}




\section{B. Main Symbols}

The main symbols used in the model formulation are defined in Table B.1.

Table B.1: Definition of main symbols

\begin{tabular}{|c|c|c|c|}
\hline Symbol & Description & Type & Unit \\
\hline I & Index of technologies & Indice & {$[-]$} \\
\hline PrPG & Power generation technology & Indice & {$[-]$} \\
\hline PrSto & Energy storage Technology & Indice & {$[-]$} \\
\hline PrTr & Energy transport technology & Indice & {$[-]$} \\
\hline $\mathrm{T}$ & Index of time steps & Indice & [h] \\
\hline $\mathrm{X}$ & Index of model regions & Indice & {$[-]$} \\
\hline Y & Index of model regions & Indice & {$[-]$} \\
\hline AVF & Availability factor & Parameter & {$[-]$} \\
\hline $\mathrm{CO}$ & Previously installed capacity & Parameter & {$\left[\mathrm{MW}_{\mathrm{el}}\right]$} \\
\hline co2Up & $\mathrm{CO}_{2}$ emissions upper limit & Parameter & [ton] \\
\hline cUp & Capacity upper limit of power plant technology & Parameter & {$\left[\mathrm{MW}_{\mathrm{el}}\right]$} \\
\hline cUpTr & Capacity upper limit of transport interconnection & Parameter & {$\left[\mathrm{MW}_{\mathrm{el}}\right]$} \\
\hline Dem & Hourly electricity load & Parameter & {$\left[\mathrm{MW}_{\mathrm{el}}\right]$} \\
\hline $\mathrm{k}^{\mathrm{Fix}}$ & Specific fixed O\&M costs & Parameter & {$\left[\$ /\left(\mathrm{MW}_{\mathrm{el} \mid \cdot \mathrm{a})]}\right.\right.$} \\
\hline$k^{\ln v}$ & Specific annual investment costs & Parameter & {$\left[\$ / \mathrm{MWh}_{\mathrm{el}}\right]$} \\
\hline $\mathrm{k}^{\mathrm{Var}}$ & Specific variable O\&M costs & Parameter & {$\left[\$ / \mathrm{MWh}_{\mathrm{th}}\right]$} \\
\hline $\mathrm{kCO} 2 \mathrm{e}$ & $\mathrm{CO}_{2}$-certificate price & Parameter & {$[\$ /$ ton $]$} \\
\hline kemf & Emission factor of power plant & Parameter & {$\left[\right.$ ton $\left./ \mathrm{MWh}_{\mathrm{th}}\right]$} \\
\hline$r(x, y)$ & Distance between regions $\mathrm{x}$ and $\mathrm{y}$ & Parameter & {$[\mathrm{km}]$} \\
\hline ramp & Ramp rate of committed or non-committed capacity & Parameter & $\begin{array}{l}{[\% \text { of maximum }} \\
\text { capacity } / \mathrm{h}]\end{array}$ \\
\hline Supim & $\begin{array}{l}\text { Wind power capacity factor; Hydropower capacity } \\
\text { factor; Solar irradiation }\end{array}$ & Parameter & {$[-] ;[-] ;\left[\mathrm{W} / \mathrm{m}^{2}\right]$} \\
\hline $\mathrm{Trl}$ & Transport losses & Parameter & $\begin{array}{l}\text { [\% of transported } \\
\text { energy } / \mathrm{km}]\end{array}$ \\
\hline
\end{tabular}




\begin{tabular}{|c|c|c|c|}
\hline W & Weighting factor of simulated time steps & Parameter & {$[-]$} \\
\hline $\mathrm{H}$ & Conversion Efficiency & Parameter & {$[-]$} \\
\hline C & Total generation capacity & Variable & {$\left[\mathrm{MW}_{\mathrm{el}}\right]$} \\
\hline $\mathrm{CN}$ & Newly installed generation capacity & Variable & {$\left[\mathrm{MW}_{\mathrm{el}}\right]$} \\
\hline CNSt & Newly installed storage reservoir capacity & Variable & {$\left[\mathrm{MWh}_{\mathrm{el}}\right]$} \\
\hline CNStin & Newly installed storage input capacity & Variable & {$\left[\mathrm{MW}_{\mathrm{el}}\right]$} \\
\hline CNStout & Newly installed storage output capacity & Variable & {$\left[\mathrm{MW}_{\mathrm{el}}\right]$} \\
\hline CNTr & Newly installed transport capacity & Variable & {$\left[\mathrm{MW}_{\mathrm{el}}\right]$} \\
\hline CSt & Total storage reservoir capacity & Variable & {$\left[\mathrm{MWh}_{\mathrm{el}}\right]$} \\
\hline CStin & Total storage input capacity & Variable & {$\left[\mathrm{MW}_{\mathrm{el}}\right]$} \\
\hline CStout & Total storage output capacity & Variable & {$\left[\mathrm{MW}_{\mathrm{el}}\right]$} \\
\hline $\mathrm{CTr}$ & Total transport capacity & Variable & {$\left[\mathrm{MW}_{\mathrm{el}}\right]$} \\
\hline$E^{\text {in }}$ & Hourly input energy (inflow) & Variable & {$\left[\mathrm{MW}_{\mathrm{th}}\right]$} \\
\hline $\mathrm{E}^{\text {out }}$ & Hourly output energy (outflow) & Variable & {$\left[\mathrm{MW}_{\mathrm{el}}\right]$} \\
\hline EStTot & Total stored energy & Variable & {$\left[\mathrm{MWh}_{\mathrm{el}}\right]$} \\
\hline ESt ${ }^{\text {in }}$ & Hourly input energy (inflow) to storage system & Variable & {$\left[\mathrm{MW}_{\mathrm{el}}\right]$} \\
\hline$E S t^{\text {out }}$ & Hourly output energy (outflow) from storage system & Variable & {$\left[\mathrm{MW}_{\mathrm{el}}\right]$} \\
\hline$E T r^{\text {in }}$ & $\begin{array}{l}\text { Hourly input energy (inflow) to transport } \\
\text { interconnection }\end{array}$ & Variable & {$\left[\mathrm{MW}_{\mathrm{el}}\right]$} \\
\hline ETr ${ }^{\text {out }}$ & $\begin{array}{l}\text { Hourly output energy (outflow) from transport } \\
\text { interconnection }\end{array}$ & Variable & {$\left[\mathrm{MW}_{\mathrm{el}}\right]$} \\
\hline z & $\begin{array}{l}\text { Total system investment, fixed, and operation costs } \\
\text { (objective function) }\end{array}$ & Variable & [\$] \\
\hline
\end{tabular}




\section{Model Calibration}

Assumed techno-economic parameters used in the model validation are represented in Table C.1. These are based on data from (Hoogwijk, 2004; Han and Ward, 2007; Roth and Kuhn, 2008; EEA, 2009; IEA, 2010; IEA, 2002; WADE, 2005; IEA and NEA, 2005; IEA, 2006).

Table C.1: Techno-economic parameters of power plants

\begin{tabular}{|c|c|c|c|c|c|}
\hline Technology & $\begin{array}{l}\text { Efficiency } \\
\qquad(\%)\end{array}$ & $\begin{array}{l}\text { Fuel price } \\
\left(\$ / M W h_{\text {th }}\right)\end{array}$ & $\begin{array}{c}\text { Variable O\&M } \\
\qquad\left(\$ / \mathbf{k W h}_{\mathrm{el}}\right)\end{array}$ & $\begin{array}{c}\text { Availability } \\
\text { (\% of maximum capacity) }\end{array}$ & $\begin{array}{l}\text { Emission factor } \\
\text { (ton/MWh }\end{array}$ \\
\hline BIO-ST & 35 & 11.4 & 0.0058 & 50 & 0 \\
\hline COAL-ST & $38-40$ & 6.6 & 0.0058 & 84 & 0.440 \\
\hline GAS-GT & 38 & 14.9 & 0.0030 & 95 & 0.308 \\
\hline GAS-CC & 52 & 14.9 & 0.0030 & 90 & 0.308 \\
\hline GEO-ST & 20 & 0 & 0.0058 & 70 & 0 \\
\hline HP-ROR & 80 & 0 & 0.0001 & 95 & 0 \\
\hline HP-PS & 80 & 0 & 0.0001 & 95 & 0 \\
\hline LIG-ST & $36-38$ & 3.3 & 0.0058 & 85 & 0.520 \\
\hline OIL-CC & 46 & 18.5 & 0.0030 & 90 & 0.473 \\
\hline OIL-GT & 30 & 18.5 & 0.0028 & 95 & 0.473 \\
\hline SOL-CSP & 15 & 0 & 0 & 99 & 0 \\
\hline SOL-PV & 12 & 0 & 0 & 99 & 0 \\
\hline URA-ST & 34 & 1.9 & 0.0008 & $70-85$ & 0 \\
\hline WIND & 96 & 0 & 0 & 95 & 0 \\
\hline WIND-O & 93 & 0 & 0 & 90 & 0 \\
\hline
\end{tabular}




\section{Techno-economic parameters of power plants}

Techno-economic parameters of power plants used in section 4.2 are determined based on data from (Han and Ward, 2007; IEA, 2010; IfE 2010; IEA, 2007; Roth and Kuhn 2008; VGB POWER TECH, 2008); these parameters are represented in Table D.1 and Table D.2.

Table D.1: Economical parameters of power plants (All costs are in EUR (2005))

\begin{tabular}{|c|c|c|c|c|c|c|}
\hline Technology & $\begin{array}{l}\text { Lifetime } \\
\text { (a) }\end{array}$ & $\begin{array}{c}\text { Investment } \\
\qquad\left(€ / \mathrm{kW}_{\mathrm{el}}\right)\end{array}$ & $\begin{array}{l}\text { Fixed O\&M } \\
\qquad\left(€ / \mathrm{kW}_{\mathrm{el}} / \mathrm{a}\right)\end{array}$ & $\begin{array}{c}\text { VariableO\&M } \\
\left(€ / \mathbf{k W h}_{\mathrm{el}}\right)\end{array}$ & $\begin{array}{l}\text { Fuel price } \\
\left(€ / M W h_{\text {th }}\right)\end{array}$ & $\begin{array}{c}\text { Emission factor } \\
\text { (ton/MWh }\end{array}$ \\
\hline BIO-ST & 25 & 2176 & 50 & 0.0105 & 15 & 0 \\
\hline COAL-ST & 40 & 1014 & 24 & 0.0037 & 7 & 0.335 \\
\hline GAS-GT & 30 & 350 & 7 & 0.0019 & 21 & 0.202 \\
\hline GAS-CC & 30 & 400 & 18 & 0.0018 & 21 & 0.202 \\
\hline GEO-ST & 25 & 2570 & 100 & 0.0001 & 0 & 0 \\
\hline HP-ROR & 80 & 1700 & 10 & 0.0001 & 0 & 0 \\
\hline HP-PS & 80 & 950 & 18 & 0.001 & 0 & 0 \\
\hline LIG-ST & 40 & 1161 & 30 & 0.0037 & 4 & 0.396 \\
\hline OIL-CC & 25 & 400 & 18 & 0.0018 & 32 & 0.310 \\
\hline OIL-GT & 25 & 360 & 12 & 0.008 & 32 & 0.310 \\
\hline SOL-CSP & 25 & 2283 & 23 & 0 & 0 & 0 \\
\hline SOL-PV & 25 & 3424 & 21 & 0 & 0 & 0 \\
\hline URA-ST & 60 & 1450 & 47 & 0.0005 & 3 & 0 \\
\hline WIND & 25 & 844 & 20 & 0 & 0 & 0 \\
\hline WIND-O & 25 & 1439 & 40 & 0 & 0 & 0 \\
\hline
\end{tabular}


Table D.2: Technical parameters of power plants

\begin{tabular}{|c|c|c|c|}
\hline Technology & $\begin{array}{l}\text { Efficiency } \\
\text { (\%) }\end{array}$ & $\begin{array}{c}\text { Ramp } \\
\text { (\% of max. capacity / hour) }\end{array}$ & $\begin{array}{c}\text { Availability } \\
\text { (\% of max. capacity) }\end{array}$ \\
\hline BIO-ST & 38 & 25 & $50^{*}$ \\
\hline COAL-ST & 40 & 22 & 84 \\
\hline GAS-GT & 35 & 100 & 95 \\
\hline GAS-CC & 52 & 35 & 90 \\
\hline GEO-ST & 20 & 25 & 70 \\
\hline HP-ROR & 80 & - & 95 \\
\hline HP-PS & 86 & - & 95 \\
\hline LIG-ST & 36 & 14 & 85 \\
\hline OIL-CC & 46 & 35 & 90 \\
\hline OIL-GT & 30 & 100 & 95 \\
\hline SOL-CSP & 25 & - & 99 \\
\hline SOL-PV & 20 & - & 99 \\
\hline URA-ST & 34 & 8 & $70-85$ \\
\hline WIND & 100 & - & 95 \\
\hline WIND-O & 100 & - & 90 \\
\hline
\end{tabular}

Notes:

*This low availability results from limited fuel availability

Development of the techno-economic parameters of power plants over the time horizon 2020-2040, which are used in section 4.3, are determined based on data from (Han and Ward, 2007; IfE 2010); these parameters are represented in Table D.3, Table D.4, and Table D.5.

Table D.3: Investment costs of new power plants (All costs are in EUR (2005)) 


\begin{tabular}{|c|c|c|c|c|c|}
\hline Technology & $\begin{array}{c}\text { Investment } \\
2020 \\
\left(€ / \mathbf{k W}_{\text {el }}\right)\end{array}$ & $\begin{array}{c}\text { Investment } \\
2025 \\
\left(€ / \mathrm{kW}_{\text {el }}\right)\end{array}$ & $\begin{array}{c}\text { Investment } \\
2030 \\
\left(€ / \mathbf{k W}_{\mathrm{el}}\right)\end{array}$ & $\begin{array}{c}\text { Investment } \\
2035 \\
\left(€ / \mathbf{k W}_{\mathrm{el}}\right)\end{array}$ & $\begin{array}{l}\text { Investment } \\
2040 \\
\left(€ / \mathrm{kW}_{\mathrm{el}}\right)\end{array}$ \\
\hline BIO-ST & 2183 & 1921 & 1690 & 1486 & 1307 \\
\hline COAL-ST & 1241 & 1216 & 1191 & 1166 & 1141 \\
\hline GAS-GT & 608 & 586 & 564 & 543 & 521 \\
\hline GAS-CC & 695 & 670 & 645 & 620 & 595 \\
\hline GEO-ST & 2580 & 2580 & 1921 & 1921 & 1921 \\
\hline LIG-ST & 1421 & 1406 & 1392 & 1378 & 1364 \\
\hline OIL-CC & 715 & 690 & 665 & 640 & 615 \\
\hline OIL-GT & 625 & 604 & 582 & 560 & 538 \\
\hline SOL-CSP & 2761 & 2522 & 2283 & 2066 & 1871 \\
\hline SOL-PV & 4080 & 3529 & 2977 & 2779 & 2580 \\
\hline URA-ST & 1489 & 1389 & 1290 & 1191 & 1092 \\
\hline WIND & 844 & 827 & 811 & 794 & 777 \\
\hline WIND-O & 1439 & 1422 & 1365 & 1327 & 1290 \\
\hline
\end{tabular}

Table D.4: Efficiency of new power plants

\begin{tabular}{|l|c|c|c|c|c|}
\hline \hline Technology & $\begin{array}{c}\text { Efficiency } \\
\mathbf{2 0 2 0} \\
(\%)\end{array}$ & $\begin{array}{c}\text { Efficiency } \\
\mathbf{2 0 2 5} \\
(\%)\end{array}$ & $\begin{array}{c}\text { Efficiency } \\
\mathbf{2 0 3 0} \\
\mathbf{( \% )}\end{array}$ & $\begin{array}{c}\text { Efficiency } \\
\mathbf{2 0 3 5} \\
(\%)\end{array}$ & $\begin{array}{c}\text { Efficiency } \\
\mathbf{2 0 4 0}\end{array}$ \\
\hline BIO-ST & 38 & 39 & 40 & 41 & 42 \\
\hline COAL-ST & 48 & 50 & 52 & 54 & 55 \\
\hline GAS-GT & 41 & 42 & 43 & 44 & 45 \\
\hline GAS-CC & 61 & 63 & 64 & 66 & 20 \\
\hline GEO-ST & 10 & 20 & 20 & 20 & 50 \\
\hline LIG-ST & 43 & 45 & 47 & 48 & 59 \\
\hline OIL-CC & 54 & 55 & 57 & 58 & 39 \\
\hline OIL-GT & 36 & 37 & 38 & & 40 \\
\hline \hline
\end{tabular}




\begin{tabular}{|l|c|c|c|c|c|}
\hline \hline SOL-CSP & 25 & 25 & 25 & 25 & 25 \\
\hline SOL-PV & 20 & 20 & 20 & 20 & 20 \\
\hline URA-ST & 34 & 34 & 34 & 34 & 34 \\
\hline WIND & 100 & 100 & 100 & 100 & 100 \\
\hline WIND-O & 100 & 100 & 100 & 100 & 100 \\
\hline \hline
\end{tabular}

Table D.5: Development of fuel prices (All costs are in EUR (2005))

\begin{tabular}{|l|c|c|c|c|c|}
\hline \hline Technology & $\mathbf{2 0 2 0}$ & $\mathbf{2 0 2 5}$ & $\mathbf{2 0 3 0}$ & $\mathbf{2 0 3 5}$ \\
$\left(\boldsymbol{\epsilon} / \mathbf{M W h}_{\text {th }}\right)$ & $\left(\boldsymbol{\epsilon} / \mathbf{M W h}_{\text {th }}\right)$ & $\left(\boldsymbol{\epsilon} / \mathbf{M W h}_{\text {th }}\right)$ & $\mathbf{2 0 4 0}$ \\
$\left(\boldsymbol{\epsilon} / \mathbf{M W h}_{\text {th }}\right)$ & $\left(\boldsymbol{\epsilon} / \mathbf{M W h}_{\text {th }}\right)$ \\
\hline Crude oil & 49.80 & 53.92 & 58.05 & 60.11 & 60.11 \\
\hline Hard coal & 10.29 & 10.62 & 10.89 & 11.11 & 11.11 \\
\hline Lignite & 3.31 & 3.31 & 3.31 & 3.31 & 3.31 \\
\hline Natural gas & 33.13 & 35.15 & 37.67 & 38.93 & 38.93 \\
\hline Uranium & 3.08 & 3.08 & 3.08 & 3.08 & 3.08 \\
\hline \hline
\end{tabular}

\section{E. Abbreviations}

\section{Abbreviations}

AFR Africa

AM America

AUS Australia

BIO All types of bio-fuels (bagasse, biogas, sewage digester gas, syngas from gasified wood or biomass, and bio-liquid fuels) or any waste (landfill gas, syngas from gasified refuse, waste gas from refinery or other industrial processes, waste heat, paper mill waste or sludges, and municipal solid waste) are aggregated to Biomass ("BIO").

CARMA Carbon Monitoring for Action

CC Combined Cycle

CSP Concentrating Solar Power

el Electrical 


\begin{tabular}{|c|c|}
\hline ENTSO-E & European Network of Transmission System Operators for Electricity \\
\hline EU & Europe \\
\hline Fix & Fixed cost \\
\hline FRES & Fluctuating Renewable Energy Sources \\
\hline GAMS & General Algebraic Modeling System \\
\hline GGI & Greenhouse Gas Initiative \\
\hline GHG & Greenhouse Gas \\
\hline GIS & Geographic Information System \\
\hline GT & Gas Turbine \\
\hline HVDC & High Voltage Direct Current \\
\hline Inv & Investment cost \\
\hline LP & Linear Programming \\
\hline NAM & North America \\
\hline NTC & Net Transfer Capacity \\
\hline O\&M & Operation and Maintenance \\
\hline PS & Pumped Storage \\
\hline PV & Photovoltaic \\
\hline $\mathrm{R}$ & Region \\
\hline RMS & Root Mean Square \\
\hline RUS & Russia \\
\hline SAM & South America \\
\hline SeaWiFS & Sea-viewing Wide Field-of-view Sensor \\
\hline SRES & Special Report on Emission Scenarios \\
\hline SSIDS & Surface Solar Irradiation Data Set \\
\hline ST & Steam Turbine \\
\hline th & Thermal \\
\hline URA & Uranium \\
\hline
\end{tabular}




\section{Var Variable Cost}

WWA World Wind Atlas 